\title{
En la horma de otros zapatos Los trabajadores inmigrantes y el enfoque de la nueva precariedad étnica
}

\author{
'In a last of other shoes' \\ Immigrants workers and the approach of the new ethnic precariousness.
}

\author{
Juan IgLesias MARTínez \\ Instituto Universitario de Estudios sobre Migraciones \\ Univ. P. Comillas (Madrid) \\ jiglesias@iem.upcomillas.es
}

Recibido: 16.06.2011

Aprobado definitivamente: 13.12 .2011

\begin{abstract}
RESUMEN
El artículo aborda la cuestión del enfoque de la nueva precariedad étnica en los países desarrollados, utilizando como ejemplo el caso de los trabajadores ecuatorianos en la región metropolitana madrileña. El análisis se despliega en tres apartados teóricos. El primero aborda la cuestión del análisis y el retrato de la precariedad de las condiciones de vida y trabajo de los migrantes en las economías desarrolladas y las relaciones entre ambas, utilizando como ejemplo el caso de los ecuatorianos en la economía madrileña. El segundo explica el papel que la reestructuración económica actual ha tenido en la incorporación de trabajadores migrantes como mano de obra barata en las regiones urbanas desarrolladas. El tercero presenta como han incidido los llamados factores sociales -clase, género, etnia, etc.- en la construcción de la nueva precariedad laboral étnica.
\end{abstract}

Palabras Clave: inmigrantes, precariedad, trabajadores, reestructuración, clase, etnicidad, género y ecuatorianos.

\begin{abstract}
The article deals with the issue of the approach of the new ethnic precariousness in developed countries, using as example the case study on Ecuadorians workers in the metropolitan area of Madrid. The analysis fans out in three theoretical sections. First, it deals with the question of the analysis and the portrait of the precariousness life and work conditions of the migrants in development economies and the relations between both, using as example the case of study on Ecuadorians in the economy of Madrid. Second, to explain the role that current economic restructuring has had in the incorporation of immigrant workers as cheap labor in the developed urban areas. Third, it presents how the so-called social factors -class, gender, ethnicity, etc.- have affected the creation of the new ethnic precariousness.
\end{abstract}

KEYwORDs: immigrants, precariousness, workers, restructuring, class, ethnicity, gender and Ecuadorians. 


\section{SUMARIO}

1.Preámbulo. 2.Primera parte. Casa y salario; el retrato de la nueva precariedad étnica. 3.Segunda parte Las causas; los orígenes económicos, sociales y étnicos de la nueva precariedad inmigrante. 4.Conclusión; un segmento social etno-estratificado al interior de la estructura social española.

\section{SUMMARY}

1. Preamble. 2. First part: House and salary: the portrait of the new ethnic precariousness. 3.Second part. The causes: the economic, social and ethnic origins of the new immigrant precariousness. 4. Conclusion: an ethno-stratified social segment within the Spanish social structure. 


\begin{abstract}
"The rapid extension of English industry could not have taken place if England had not possesed in the numerous and impoverished population of Ireland a reserve at command. (...) and from the time when it became known in Ireland that the east side of St. George's Channel offered steady work and good pay for strong arms, every year has brought armies of the Irish hither. It has been calculated that more than a million have already inmigrated, and not far from fifty thousands still come every year, nearly all of whom enter the industrial districts, especially, the great cities and there form the lowest class of the population." (Engels, (1845) 1980: 116).
\end{abstract}

\section{PREÁMBULO}

En lo últimos 20 años, el fenómeno de la migración internacional de carácter laboral procedente de países en desarrollo ha irrumpido con inusitada fuerza en la realidad y en la literatura de la pobreza y la precariedad en España. ${ }^{1}$ Los trabajadores inmigrantes se han convertido, así, en una nueva y emergente figura social que no solo ha propiciado el creciente proceso de transnacionalización de la economía y el mercado de trabajo español, o el profundo cambio de la realidad socio-cultural del país, sino que, también y especialmente, dadas sus vulnerables condiciones de incorporación socioeconómica, fundamentalmente como trabajo barato y flexible, ha generado una auténtica conmoción en los cimientos de los procesos de estratificación social en España, en la medida en que se convertían en uno de los segmentos más débiles y novedosos del panorama actual de la pobreza y la precariedad. ${ }^{2}$

Una irrupción inesperada, además, que no solo ha provocado un cambio sustancial en los trazos de la realidad de la pobreza y la estratificación social en España sino que, al tiempo, ha forzado la necesidad de afrontar cambios teóricos sustanciales en la tradición de la sociología de la pobreza en España. De esta forma, la literatura sobre la pobreza asaltado por la fuerza social de una realidad donde la presencia de estos nuevos obreros globales precarizados era cada vez mayor, se ha visto impelida, urgida, a incorporar en su agenda de investigación y en su quehacer teórico y metodológico, las novedades conceptuales e históricas que la realidad de la migración laboral internacional imponía. Algo que, necesariamente, pasaba por ampliar y tensionar sus formas y hormas tradicionales de pensar los procesos de precarización, pobreza y estratificación social o, si se quiere, por la tarea de aumentar sus lentes de análisis tradicional con el fin de acuñar e incorporar nuevos conceptos y enfoques de pensamiento que, al ampliar la mirada teórica, le posibilitaran explicar la presencia y la precariedad de estos nuevos trabajadores migrantes, esto es, el nuevo componente étnico de la precariedad en los países desarrollados.

Una solicitud esta, de análisis y renovación teórica y metodológica de la sociología de la pobreza a la luz de la migración internacional, que se ha visto truncada, en ocasiones, al generarse una cierta tendencia a reproducir mecánicamente las viejas categorías de pensamiento acerca de la pobreza y la precariedad sobre el fenómeno inmigrante; truncada, pues, por unas categorías que se mostraban, generalmente, impotentes, agostadas, en la tarea de comprender y aprehender la nueva realidad social inmigrante. Así, frente a la nueva precariedad étnica la literatura ha caído en ciertos automatismos, recurriendo, en ocasiones, al arsenal teórico preponderante en los años ochenta y noventa en España, esto es, recurriendo al paradigma de la pobreza, la marginación social y la exclusión social, ${ }^{3}$ paradigmas que se mostraban netamente insuficientes para dar cuenta en profundidad de la nueva situación so-

\footnotetext{
${ }^{1}$ En el año 2008 España contaba con una población extranjera de 5,22 millones, el 11,3\% de la población total. Veinte años atrás, la cifra de extranjeros era tan solo de 360.000. Un crecimiento, igualmente vertiginoso e inesperado, que ha mudado la realidad económica y laboral del país. (INE, 2008 y AEE, 2008).

${ }^{2}$ Por ejemplo, en el VI Informe FOESSA, vuelve a confirmarse la emergencia y la consolidación de la inmigración extracomunitaria como rostro de la nueva pobreza en España. (Foessa, 2008).

${ }^{3}$ Por ejemplo, los inmigrantes se ven envueltos “en procesos más generales de exclusión social (...) en la vivencia de condiciones sociales secundarizadas y marginales muy parecidas a las de las infraclases sociales” (Tezanos, 2007).
} 
cial de los trabajadores inmigrantes. De tal forma que lo que más bien se ha producido es un ajuste de los inmigrantes y sus condiciones de vida y trabajo, a los formatos teóricos que sobre la pobreza se venía manejando en la literatura en los últimos veinte años, y no lo contrario, esto es, la reformulación y ensanchamiento de la teoría a partir de las nuevas realidades y retos específicos que plantea la migración internacional.

Resumiendo, se podría decir que la condición social de la migración laboral internacional, una condición que no termina de caber del todo en los parámetros tradicionales que ofrecen los formatos teóricos vigentes acerca de la pobreza y la desigualdad, ha sido forzada a encajar en esas viejas hormas de interpretación, y lo ha sido a fuerza de percutir golpes conceptuales sobre su realidad, a fuerza, por tanto, de calzar su situación en una horma teórica estrecha que, en ocasiones, solo ha conllevado la deformación y distorsión del propio objeto de estudio que se investigaba.

Tomando en cuenta esta situación lo que se pretende en este artículo, además de presentar algunos de los rasgos de la nueva precariedad étnica que surgen a partir del estudio de un caso concreto, es exponer y ofrecer a discusión una propuesta de análisis de las condiciones de precariedad de los trabajadores inmigrantes construida a partir de la literatura existente sobre las migraciones internacionales y la nueva pobreza. ${ }^{4}$ Una propuesta de análisis, por tanto, que recogiendo elementos de la tradición teórica existente en la sociología de la pobreza y, especialmente, en la sociología de las migraciones internacionales, trata de presentar y subrayar nuevas formas de abordar teóricamente la precariedad étnica. Un enfoque de estudio que pretende no solo analizar y caracterizar las condiciones de vida y trabajo precarizadas de amplios sectores de la inmigración económica en las sociedades de acogida, haciendo especial hincapié en las íntimas conexiones existentes entre ambos sino, también y al mismo tiempo, profundizar en los procesos estructurales económicos y sociales que aparecen en la génesis de esta nueva precariedad inmigrante $\mathrm{y}$, en última instancia, en la formación y consolidación de un bloque social proletarizado y étnicamente segmentado al interior y abajo de la estructura social de los países desarrollados.

En las páginas siguientes se presentaran las principales coordenadas de este enfoque de análisis pero antes de exponerlo es conveniente enmarcar brevemente la reflexión que se va a hacer. Antes de nada y en primer lugar, hay que decir que se trata, fundamentalmente, de una propuesta de corte analítico que trata de proponer para su discusión, un marco de abordaje y análisis de las nuevas condiciones de precariedad de los inmigrantes en España, condiciones que están en la base de los actuales procesos de etnoestratificación y segmentación social. En segundo lugar, hay que apuntar que la propuesta de análisis que se va a presentar aparece ejemplificada y articulada a los resultados de la tarea investigadora desarrollada en los últimos años sobre las condiciones de vida y trabajo de los inmigrantes ecuatorianos en la región madrileña. De esta forma, y es necesario subrayarlo, las específicas condiciones de precariedad que se presentan, aunque pudieran ser un aporte a la literatura sobre la cuestión desde las coordenadas concretas de un caso de estudio, no pretenden agotar, en ningún caso, ni la realidad de la precariedad de la migración internacional en España ni, mucho menos, la realidad de la inmigración en general, un espacio social donde, además de las situaciones de precariedad, existe una amplia diversidad de trayectorias sociales, incluyendo la de aquellos colectivos,

${ }^{4}$ Este artículo se ha construido a partir de la investigación doctoral realizada mediante el método biográfico sobre las condiciones de vida y trabajo de inmigrantes ecuatorinos en Madrid entre los años 2002-2004. Una investigación, dirigida por el profesor JJ. Castillo, que salió mejorada, discutida y ampliada tras el paso por las Jornadas que sobre Migraciones, Trabajo y Cadenas Globales Agrícolas se celebraron en enero de 2009 en la Universidad de Murcia bajo la coordinación del profesor Andrés Pedreño. Finalmente, el trabajo de investigación con ecuatorianos tuvo una segunda fase de campo ligada al proyecto del Plan Nacional de I+D+I (CSO2009-10429) donde, nuevamente, se ahondó e investigo sobre sus condiciones de vida y trabajo, en esta ocasión, en los años inmediatamente anteriores a la crisis: 2006-2008. En total, se realizaron treinta y dos y quince entrevistas a trabajadores ecuatorianos, respectivamente, y ocho y cinco entrevistas a trabajadores sociales de centros de atención de inmigrantes. Las específicas coordenadas de precariedad que se presentan en este artículo están referidas a esos dos procesos de investigación. Aunque, se debe subrayar, nuevamente, que es un artículo dirigido a la exposición de un determinado enfoque de abordaje y análisis de la precariedad laboral y vital de los inmigrantes en los países desarrollados. 
familias e individuos que inician procesos de movilidad social ascendente escapando, así, de dichas situaciones de precariedad (Cachón, 2009). Se presenta, pues, un enfoque o un esquema de análisis de la nueva precariedad étnica utilizando para ello el retrato de las condiciones de precariedad de los trabajadores inmigrantes ecuatorianos en la región madrileña.

\section{PRIMERA PARTE CASA Y SALARIO; EL RETRATO DE LA NUEVA PRECARIEDAD ÉTNICA}

Se trata, en este apartado, de presentar la forma específica en que se abordan las condiciones de precariedad étnica desde este tipo de enfoque, a través de la descripción las condiciones de vida y trabajo de los migrantes ecuatorianos en la región madrileña. Unas claves de análisis que no solo envuelven el hogar o el espacio comunitario, sino también, el ámbito del trabajo y la producción, el espacio de la "fabrica". Se opta, así, por un planteamiento que aborda la pobreza y la precariedad de los inmigrantes desde una perspectiva más amplia, que incluye y reconstruye junto a las condiciones de vida, las condiciones de trabajo y que lo hace, además, mostrando la íntima ligazón que tienen entre sí ambos elementos a la hora de explicar y describir la precariedad. Un enfoque, además, que prima junto a la reconstrucción del trabajo y las condiciones de trabajo, su engarce en las cadenas productivas actuales. Pasemos a continuación a mostrar, brevemente, estas claves de análisis a través de la exposición de los rasgos esenciales de la precariedad en el caso de los migrantes ecuatorianos.

\subsection{Dentro de las fábricas. Las condiciones de trabajo}

Sobre el trasfondo de la reestructuración económica, y la formidable demanda de trabajo barato y flexible que esta generó, se fueron incorporando, de forma vertiginosa, desde finales de los años noventa, los trabajadores ecuatorianos al contexto español. Unos trabajadores migrantes deslocalizados hacia el mercado de trabajo español, que, paulatinamente, fueron apareciendo en el descentralizado sistema productivo nacional de bienes y servicios como trabajo obrero, fluido y barato, incorporado, en aquellas empresas y ocupaciones más degradadas de las nuevas cadenas productivas. En, si se quiere, aquellos segmentos productivos informalizados $\mathrm{y}$, en ocasiones, sumergidos que representaban el final de los procesos de subcontratación productiva que la reestructuración había provocado (Gallino, 2003; Pedreño y $\mathrm{G}^{\mathrm{a}}$ Borrego, 2005). Trabajos y trabajadores, al final de las cadenas (Castillo, 2002), que al tiempo, fueron emergiendo en la realidad social madrileña bajo condiciones de vida muy precarizadas; pisos, o barracones de trabajo, degradados, ingresos económicos escasos e irregulares, incluyendo periodos de pobreza extrema, irregularidad y vulnerabilidad jurídica, etc. Condiciones de vida y trabajo que la investigación sobre la migración internacional ecuatoriana fue, progresivamente, dejando al descubierto desde finales de los años noventa.

De esta forma, y siguiendo el hilo de la investigación realizada, si nos centramos, en un primer momento, en desglosar y perfilar las ocupaciones y los sectores de ocupación de los inmigrantes ecuatorianos, el retrato resultante muestra la aparición de una franja de trabajo degradado dentro de la economía madrileña cuyos rasgos más sobresalientes son los siguientes:

\subsubsection{Las ocupaciones}

Desde la segunda mitad de los años noventa las mujeres migrantes ecuatorianas son incorporadas como trabajadoras manuales, flexibles y baratas, en el sector, en expansión, de servicios domésticos (Herranz, 1997; Martínez Veíga, 1997; Parella, 2000 y Colectivo IOE, 2001). Las migrantes se incorporan, así, a un espacio laboral profundamente deteriorado por sólidas dinámicas de género, clase y etnia, y lo hacen desempeñando todas las tareas tradicionales del sector; cuidado de niños, trabajos del hogar y cuidado y atención de ancianos. Unas trabajadoras domésticas extranjeras que aparecen, en un primer momento, bajo la modalidad de interna, aquella que reúne las peores condiciones del sector; trabajo sumergido e invisibilizado, salarios bajos, jornadas laborales interminables en tiempo y carga de trabajo, intensificación laboral, aislamiento y desregulación del vínculo laboral, incluyendo un generalizado proceso de difuminación de la frontera entre tiempo de trabajo y tiempo de descanso, etc. 
Un sector de trabajo manual de servicios que es aceptado por las migrantes ecuatorianas como forma de sacar adelante el proyecto migratorio familiar, ya que, el trabajo de interna les permite penetrar en el mercado de trabajo español, para luego, generalmente, abandonarlo en cuanto se consiguen algunos de los primeros objetivos migratorios; saldar la deuda, jalar algún familiar al mercado de trabajo español, acumular ahorros, regularizar la situación, etc. Dirigiéndose, posteriormente, a otros sectores de trabajo o hacia el mismo sector doméstico, pero esta vez bajo la modalidad de externa. De esta forma, en los primeros tiempos del proyecto migratorio, los magros salarios del trabajo femenino en el servicio doméstico se convierten en una fuente de recursos central para las ecuatorianas y sus familias y comunidades de origen y, también, en la base fundamental sobre la que se construyen y sufragan nuevos procesos migratorios; el cimiento, por tanto, de la migración internacional como estrategia de sobrevivencia $\mathrm{y}$ futuro frente a los procesos de empobrecimiento presentes en sus contextos de origen.

Un sector de trabajo, en resumen, feminizado y fuertemente sobre-explotado, donde convergen en un único crisol de desigualdad las distintas asimetrías de clase, género y etnia, con la peculiaridad, en principio contradictoria, de que los principales empleadores del sector $\mathrm{y}$, por tanto, los principales definidores de las relaciones laborales son, generalmente, mujeres nativas procedentes de sectores de clase media. Mujeres que, mayoritariamente, pertenecen a una generación sociológica femenina que por primera vez en España ha tenido un acceso generalizado a niveles educativos superiores y al mercado de trabajo profesional y que, de forma inesperada, ha terminado por transferir las cargas desiguales de género hacia las relaciones y condiciones de trabajo de otras mujeres de diferente clase y origen social, en este caso, mujeres migrantes procedentes de países en desarrollo.

Un segundo sector tradicional de incorporación de los trabajadores inmigrantes ecuatorianos ha sido el trabajo asalariado, en precario, en el complejo agroindustrial y exportador español, localizado, pre- ferentemente, en la franja mediterránea de la península. ${ }^{5}$ Los trabajadores ecuatorianos, de esta forma, han sido reclutados, de forma creciente y masiva, para desempeñar aquellas tareas de trabajo directo y manual ligadas a las fases intensivas de la producción de frutas y hortalizas; recolección, envasado, etc. Un segmento étnico de trabajo rural que ha reproducido muchas de las condiciones clásicas del jornalerismo agrario; desregulación laboral, rotación, trabajo a destajo, salarios bajos e irregulares, intermediación, trabajo sumergido, alta movilidad ocupacional y territorial, etc. y que, al tiempo, se ha convertido, no solo, en una fuente de ingresos clave para los migrantes y sus familias, sino sobre todo, en una fuente de trabajo global, depreciado y flexible, imprescindible para entender los procesos de competitividad, nacional e internacional, y de rentabilidad de un sector primario formado, principalmente, por pequeñas y medianas empresas productivas. (Pedreño, 2003).

Un tercer sector de actividad central donde se ha ido incorporando, paulatinamente, la mano de obra inmigrante ecuatoriana ha sido el sector de la construcción. Los inmigrantes han ido emergiendo, así, como peones de ejecución, baratos y flexibles, en las heterogéneas cadenas de pequeñas y medianas empresas y subcontratas que constituyen actualmente el sector de la construcción, y lo han hecho incorporándose, precisamente, en aquellos segmentos y eslabones productivos más débiles, degradados e informalizados de esta nueva fábrica fluida que es, hoy, la construcción. Así, estos migrantes laborales procedentes del tercer mundo aparecen trabajando bajo una fuerte diversidad de modalidades laborales y productivas; desde el contrato informal en una "peonada" semanal para un pequeño pistolero dedicado a la reforma privada, hasta el trabajo formal de peón o albañil cualificado que trabaja por obra y servicio para alguna empresa formal incorporada como subcontrata en alguna gran obra civil de infraestructuras tecnológicas o de transporte de la región. Pasando por el trabajo de obrero de ejecución, formal e informal, para pequeñas subcontratas que se incorporan en alguna de las fases de trabajo intensi-

\footnotetext{
${ }^{5}$ Incluyo esta ocupación porque, en múltiples ocasiones, los migrantes ecuatorianos a pesar de situarse en Madrid y debido su alta disponibilidad a la movilidad laboral y geográfica, han utilizado estos salarios jornaleros como fuente de trabajo temporal que compensaban o complementaban los salarios en la economía madrileña.
} 
vo de la construcción de viviendas residenciales; o, en ocasiones, por el trabajo intensivo en cuadrillas étnicas de producción especializadas en alguna de las fases de trabajo directo de la obra. Los migrantes ecuatorianos se incorporan, pues, generalmente, como trabajo bruto, físico, de ejecución y, por tanto, como trabajo flexible, abundante y disponible, trabajadores, pues, que además de estar ligado a los segmentos más débiles de la miríada de cadenas de subcontratación del sector, desempeña algunas de las tareas más duras, pesadas y rutinarias. Trabajo manual en estado fluido, que entra y sale de la obra constantemente, y donde la modalidad de trabajo central es el trabajo a temporadas. Trabajo bajo relaciones laborales profundamente desreguladas, donde se producen jornadas interminables ajustadas fielmente a la demanda productiva, o riesgos en la seguridad, impagos, etc. Trabajo, muchas veces, sumergido o incluso, literalmente invisibilizado, hasta el punto de que, en ocasiones, los migrantes ecuatorianos forman parte de obras y empresas que cuentan, al tiempo, no solo con trabajadores formales, sino también con una especie de trabajadores y cuadrillas sombra, opacas, que trabajan informalmente, como, por ejemplo, subcontratas de la construcción con un turno étnico de trabajo sumergido por la noche, o cuadrillas de peones manuales sin contrato trabajando, literalmente, bajo tierra en la construcción de túneles del metro o en el tendido del cableado de fibra óptica de la ciudad. Trabajo, en definitiva, incorporado a paletadas en el sector, tras ser reclutado en redes sociales étnicas, o en alguna de las múltiples plazas urbanas, que se convierten, de esta forma, en mercados de trabajo al día, en centros de abastecimiento de trabajo jornalero en el interior del espacio urbano (Valenzuela, 2006).

En cuarto lugar, los inmigrantes ecuatorianos aparecen como trabajadores manuales, baratos y flexibles, incorporados a lo largo y ancho de las nuevas cadenas de empresas descentralizadas que componen, hoy, el heterogéneo sector de servicios urbanos de bajos salarios (Sassen, 1988); peones de servicios empleados por subcontratas de agencias de publicidad que se encargan de montar y desmontar los rótulos de los cárteles publicitarios; limpiadores externalizados por horas de los we de restaurantes y cafeterías, chóferes de empresas de renting, buzoneadores de publicidad con jornal y ruta variable, ayudantes de pequeños comercios, mozos de alma- cén y, en general, personal de carga y descarga del sector de la distribución de alimentos, muebles, etc., cajeras y reponedores de supermercados, porteadores a jornal de servicios en transportes y mudanzas, repartidores a domicilio de alimentos, transportistas, operarios de jardinería, obreros manuales de la rama de lavanderías industriales, etc. Un extenso y heterogéneo tapiz de trabajo obrero de servicios del que es necesario entresacar algunas de sus figuras más relevantes:

Primera, el trabajo, generalmente femenino, en las descentralizadas cadenas empresariales del sector de limpieza. Las mujeres migrantes ecuatorianas aparecen, así, trabajando como obreras de servicios en las múltiples subcontratas del sector; desde la pequeña empresa familiar de ámbito local hasta la gran empresa de ámbito nacional. Trabajadoras extranjeras dedicadas, en jornadas variables, a la limpieza de todo tipo de empresas, instituciones, establecimientos y comunidades de vecinos, y reclutadas bajo múltiples y variadas modalidades laborales; desde el trabajo informal y regular a jornal o por horas, hasta el empleo regular indefinido. Un trabajo marcado, generalmente, por la desregulación de las relaciones laborales, los bajos salarios y la intensificación, esto es, por faenas y jornadas de trabajo donde la carga laboral suele ser superior al horario de trabajo.

Segunda, los jornales escasos y estacionales del sector del turismo. Así, dentro de las rutas de movilidad laboral de los migrantes ecuatorianos en la economía española aparece como segmento de ocupación el sector turístico, ligado no solo a las altas temporadas vacacionales, sino al trasiego constante de turistas en numerosas localidades del país y, en especial, en el territorio madrileño. Los ecuatorianos, y de forma especial la mano de obra femenina, aparecen así como trabajadores manuales del sector, desempeñando, bajo condiciones de fuerte desregulación e intensificación laboral, todas esas tareas obreras de servicios que componen el entramado productivo interno del sector en ramas tan diferentes como la hostelería, la restauración, el pequeño comercio, los servicios de transporte y atención, la seguridad, etc. Braceros del ocio, figuras laborales degradadas del sector servicios que terminan convirtiéndose en un insumo económico central, dados sus costes salariales bajos y su enorme flexibilidad laboral (Pedreño y Castellanos, 2007b). Trabajo obrero de servicios, por tanto, fuertemente articula- 
do en las estrategias empresariales claves de uno de los sectores centrales de la expansión económica española. Un sector de baja productividad e intensivo en trabajo y, por tanto, necesitado de la presencia abundante e irregular de la mano de obra barata que representa la migración laboral internacional.

Tercera, el trabajo manual en los llamados servicios comunitarios y personales. El crecimiento de la mano de obra inmigrante ha estado vinculado al crecimiento de una nueva clase media profesional, ligada al proceso de reestructuración y tercerización avanzada del actual capitalismo global. Un sector social de ingresos medios y altos que, ya sea porque ha demandado directamente toda una serie de servicios ligados a sus nuevos estilos de vida y lugares de residencia; jardinería, seguridad, pequeño comercio, transporte, etc., ya sea porque ante la disponibilidad del caudal barato y desregulado de trabajo que representa la migración laboral, se haya decidido a externalizar o contratar esos servicios para sus hogares, se ha convertido en un motor de arrastre e incorporación clave de los trabajadores inmigrantes en el contexto español y, en concreto, de los migrantes ecuatorianos. Así, especialmente en la región madrileña, los ecuatorianos aparecen como obreros fluidos y baratos de servicios, desempeñando tareas manuales ligadas a este segmento de actividad tan unido a la nuevas clases medias urbanas; obreros en reformas caseras, guardias de seguridad, porteros, chóferes, repartidores a domicilio, pequeños portes, pequeños arreglos caseros, peones de jardinería, construcción de piscinas, etc. Un segmento de trabajo obrero terciario, degradado y etnificado, que se constituye como el otro rostro de la alta terciarización globalizada; un rostro invisibilizado, tantas veces, en los debates sobre la transformación actual de las economías desarrolladas.

Cuarta, el trabajo manual en el sector de la hostelería. Los trabajadores inmigrantes ecuatorianos aparecen, de esta forma, desempeñando todo tipo de tareas físicas y manuales de servicios en este segmento de actividad: camarero, carga y descarga, pequeñas compras, distribución y reparto, cocina, limpieza del local, limpieza de cocina, etc. Y, en múltiples ocasiones, desempeñando todas, o casi todas, las tareas a la vez, hasta el punto de emerger la figura del trabajador hostelero "completo"; un obrero inmigrante de servicios encargado de trabajar en todas las fases del trabajo manual del negocio. Un sector, el de la hostelería, donde, también, aparecen procesos de descentralización de la "producción" apoyados en trabajo inmigrante en este caso ecuatoriano, como, por ejemplo, restaurantes con cocinas étnicas subcontratadas, esto es, cocinas deslocalizadas del restaurante central con mano de obra inmigrante, generalmente informal, que en otro lugar hacen la comida para la casa matriz.

Y quinta, los ecuatorianos aparecen, finalmente, bajo la figura del obrero total de servicios. Una figura laboral, desregulada y barata de la nueva precariedad étnica en los países desarrollados que desempeña todas las tareas y trabajos manuales que las múltiples empresas de servicios urbanos requieren; carga y descarga, limpieza, chofer, pequeños encargos y recados, mensajería, compras, jardinería, arreglos del local, etc. Un trabajador terciario desregulado que se convierte en trabajo manual en bruto, disponible, de esta forma, para todas las tareas manuales de las empresas de servicios.

Por último, en quinto lugar, habría que hablar del trabajo de los inmigrantes ecuatorianos en la nueva manufactura industrial, descentralizada y dispersa, de las economías desarrolladas. Un sector que pese a su importancia en la literatura ${ }^{6}$ ha pasado, prácticamente, de puntillas por la sociología de las migraciones en España, eclipsado, probablemente, por los procesos de deslocalización internacional de la producción industrial. Sin embargo, los migrantes ecuatorianos aparecen plenamente incorporados como obreros fabriles en las cadenas productivas de sectores como la industria textil, el calzado, el metal y el mueble, o la pequeña agroindustria urbana. Los ecuatorianos se incorporan, pues, como trabajo manual en algunos de los cientos de pequeños y medianos talleres que hoy conforman la dispersa y fragmentada industria de los países desarrollados, desempeñando, generalmente, tareas y ocupaciones de ejecución en diferentes procesos productivos: trabajadores manuales de distinta calificación en la pequeña industria del mueble y el metal ligada, mayo-

\footnotetext{
${ }^{6}$ Sassen, (1988) y Phizacklea, (1990) ya hablan de la presencia de un sector degradado de fabricación donde aparecen, junto a mano de obra nativa, migrantes laborales.
} 
ritariamente, al auge de la industria de las construcción; trabajos formales y sumergidos en pequeños talleres textiles localizados en el centro de la ciudad o en la periferia metropolitana; trabajadoras manuales, formales e informales, dedicadas de forma intensiva al aparado en pequeñas factorías industriales del calzado localizadas en zonas periféricas urbanas y rurales de la región madrileña; obreras agroindustriales realizando tareas de procesamiento, envasado y distribución -y, en ocasiones, todas a la vez- en industrias dedicadas al procesado y comercialización de productos alimentarios. Los inmigrantes ecuatorianos, aparecen, pues, como obreros industriales desregulados y baratos incorporados en las nuevas cadenas descentralizadas de empresas, centros de trabajo y trabajadores que, hoy, componen, la nueva industria ligera dispersa a lo largo y ancho del territorio. Un sector de fabricación, miniaturizado y degradado, donde junto al trabajo formal emerge, en los mismos procesos productivos, articulado al formal, el trabajo clandestino, esto es, trabajo y trabajadores inmigrantes sumergidos, sin contrato.

\subsubsection{Las condiciones de trabajo}

Los trabajadores ecuatorianos, pues, aparecen incorporados al final de los cadenas de producción actuales, en segmentos de elaboración de bienes y servicios, externalizados y degradados, desempeñando todo tipo de tareas intensivas en trabajo $\mathrm{y}$, generalmente, bajo relaciones salariales notablemente deterioradas. Un estatuto laboral débil cuyos rasgos centrales ${ }^{7}$ se pueden desglosar de la siguiente forma:

Los migrantes ecuatorianos aparecen, generalmente, como trabajadores altamente disponibles en el mercado de trabajo, trabajadores dispuestos a trabajar en lo primero que se presente. Una mano de obra, abundante y barata, situada, permanentemente, en las entradas del mercado de trabajo, disponible para ser reclutado e incorporado en la nueva economía productiva descentralizada. Estos inmigrantes procedentes de países en desarrollo aparecen, pues, como obreros manuales vulnerables con escasa, o casi nula, capacidad de negociación y resistencia, tanto a la hora de establecer sus condiciones de trabajo y su relación salarial, como, una vez dentro del mercado de trabajo, para plantear demandas o rebajar determinados requerimientos laborales de sus empleadores. Una oferta abundante de trabajo inmigrante que, en numerosas ocasiones, es convertida en mano de obra efectiva a través de la figura clave del enganchero o intermediario étnico; esto es, aquel migrante, hombre y mujer, que tiene un pie puesto en las redes sociales migratorias y otro en el mercado de trabajo etnificado. Una posición social, por tanto, que actúa de puente laboral, posibilitando el reclutamiento de trabajadores inmigrantes, incluso de forma transnacional, para el mercado de trabajo español.

En esta línea, de alta disponibilidad laboral, tejida y urgida por una fuerte precariedad económica y social, es necesario hablar del crecimiento en los últimos quince años de mercados de trabajo al día en algunos espacios urbanos y, en concreto, en Madrid al hilo del ascenso de la migración laboral internacional. Espacios de reclutamiento de trabajo al día, donde todas las mañanas se reúnen y concentran trabajadores inmigrantes con el fin de ser reclutados, enganchados, bajo condiciones formales o informales, para el desempeño de alguna tarea manual en la construcción, la agroindustria o los servicios. Mercados de trabajo diarios, fluidos y opacos, que han proliferado en el contexto español de expansión económica y migración internacional, y que aparecen como un retrato paradigmático de la disponibilidad de mano de obra inmigrante vulnerable en la economía española y madrileña.

En segundo lugar, los trabajadores ecuatorianos se han incorporado a la economía madrileña como trabajo obrero manual en los segmentos más descentralizados de las cadenas productivas actuales. En espacios económicos donde se acumulan, por tanto, ocupaciones de ejecución, esto es, trabajos marcados por tareas rutinarias y descalificadas, vaciadas de contenido. Los inmigrantes aparecen, así, como obreros manuales dentro de procesos y relaciones productivas y laborales fuertemente fragmentadas e intensificadas y, en múltiples ocasiones, como pura mano de obra de ejecución, como trabajo, por tanto,

${ }^{7}$ Algunas fuentes esenciales relativas a las condiciones de trabajo de los inmigrantes en España son: (Martínez Veiga, 1997; Herranz, 1997; Colectivo IOE, 2001; Pedreño y García Borrego, 2005; Pedreño, 2007a y Cachón, 2009). 
desmigajado, manualizado, en bruto, trabajo de cundir, físico, reducido a sus operaciones más simples y desgajado de cualificaciones y saberes productivo, aunque, eso sí, al mismo tiempo, plenamente articulado en la producción actual de bienes y servicios.

Los ecuatorianos emergen, también, en el sistema productivo madrileño como trabajadores altamente flexibilizados en, al menos, dos sentidos. Primero, al interior de la organización de trabajo, como empleados profundamente flexibilizados en horario y jornada, en tareas y cargas de trabajo, en tiempos y ritmos de trabajo. Y segundo, en relación al vínculo salarial, esto es, como trabajadores globales ocupados bajo relaciones laborales fuertemente desreguladas, convertidos en trabajo eventual, temporal y, en ocasiones, sumergido que se incorpora, de forma flexible y ligera a la producción actual de las economías desarrolladas. Hasta el punto de que se desarrollan, no solo en el ámbito rural sino también, en el urbano, pautas de relaciones laborales jornalerizadas, es decir, de trabajo y salario en bruto reclutado al día, por jornada, por horas, por peonada o tarea de trabajo. Un escenario laboral flexibilizado, además, donde al final de estos procesos de desregulación de la producción y el trabajo surge la figura del trabajador informalizado, aquel que compone la otra mano de obra de las empresas y centros de trabajo formales pero que, al tiempo, aparece plenamente incorporado, articulado, en los procesos de fabricación directa de los bienes y servicios de nuestras sociedades. Trabajadores ligeros en estados de excepción laboral que son incorporados, de esta forma, en la cantidad, la intensidad y el coste ajustado a las necesidades laborales y económicas de cada momento y de cada organización productiva. Trabajadores inmigrantes, pues, que emergen en la economía española como trabajo en estado fluido, liofilizado, trabajo que se amolda, casi perfectamente, a los ritmos y requerimientos de la producción actual ensanchando los límites de las estrategias de rentabilidad y permitiendo un ajuste ideal del trabajo a los tiempos y exigencias de la demanda ${ }^{8}$.

El trabajo de los ecuatorianos, por último, se caracteriza por ser un trabajo intensificado y abaratado.
Trabajo, por un lado, convertido en ocupaciones y tareas de ritmos laborales altos, "apurados", trabajo "a las carreras", donde la carga de trabajo suele ser más alta que el horario laboral reclutado, contratado o pagado. Trabajo, pues, fuertemente intensificado a través de diversas figuras y modalidades laborales; el pago a destajo, la constante presencia de un capataz laboral, incluso en el servicio doméstico, o, sencillamente, por la urgente presión de permanecer en el trabajo. Ritmos y jornadas de trabajo elevadas con ocupaciones muy físicas que terminan, en múltiples ocasiones, literalmente, extenuando corporal y mentalmente a los trabajadores. Ritmos de trabajo apurados que, además, se combinan con una situación residencial y unos tiempos de descanso fuera de las "fábricas" descentralizadas reducidos y precarios, dando lugar, de esta forma, a procesos crecientes de deterioro personal y anímico.

Trabajo, finalmente, en líneas generales, y más allá de las variaciones por sectores y ocupaciones, barato, de salarios bajos e irregulares; desde las medias jornadas de externas en el sector doméstico con salarios de menos de 300 euros, a los 900 o 1000 euros de salario por una jornada completa en el sector de la construcción. De los jornales diarios a veinte o treinta euros en el campo o en la construcción o los 500 o 600 euros de salario mensual en el trabajo de interna en el servicio doméstico o en una contrata de limpieza de comunidades. Relaciones salariales, en definitiva, regidas, por un principio maximizador que tiende a extraer la mayor cantidad de trabajo posible al menor precio. ${ }^{9}$ Ocupaciones de salarios bajos que suelen crecer, habitualmente, en contextos socio-económicos donde el mercado laboral se encuentra, metafóricamente, anegado de mano de obra vulnerable; donde hay, por tanto, una fuerte concurrencia laboral de trabajadores empobrecidos y vulnerables.

\subsection{Fuera de las fábricas. Las condiciones de vida}

Ahora bien, junto a estas características laborales precarias e íntimamente ligadas a ellas, esto es, como su resultado y origen al mismo tiempo,

\footnotetext{
${ }^{8}$ En este caso, la flexibilidad no es más que una caricatura de la precariedad del trabajo. (Castillo, 2002)

9 "Extraer con la menos cantidad posible de dinero la mayor cantidad posible de trabajo" (Marx. Citado en Pedreño, 2007a: 228)
} 
emergen unas condiciones de vida fuera del trabajo marcadas igualmente por la precariedad y la vulnerabilidad. Unas condiciones de vida caracterizadas, por tanto, por la presencia de ingresos escasos e irregulares, por la constante incertidumbre e inseguridad laboral, económica, vital, por la irregularidad y vulnerabilidad jurídica, por la debilidad y precariedad residencial y por unos tiempos vitales, fuera del trabajo, escasos, débiles y fuertemente vigilados y prejuiciados étnicamente, como si los migrantes laborales debieran evaporarse, o invisibilizarse, con el sonido de la sirena del fin del trabajo. Una precariedad étnica, en resumen, cuyos rasgos se pueden desglosar de la siguiente forma:

Primero, una situación caracterizada por la precariedad socio-económica. Así, las economías migratorias de estos trabajadores deslocalizados en la región madrileña, se caracteriza, fundamentalmente, por la escasez y la irregularidad de sus ingresos. Una situación que no es sino el reflejo, la proyección, de sus condiciones laborales y salariales, de sus jornales baratos y flexibles, el negativo, si se quiere, de aquello que constituye la principal, y casi única, fuente de ingreso de los trabajadores inmigrantes en los países de destino. Una situación económica, está, que debilita y precariza sus condiciones de vida, afectando y empobreciendo, especialmente, todas aquellas partidas del gasto doméstico básico que tienen que ver con las necesidades más elementales; alimentación, vivienda, ropa, salud, transporte, etc. De esta forma, por ejemplo, se constata, en algunas etapas o momentos de la migración laboral, la aparición de dietas alimenticias muy débiles, dietas que, prácticamente, se pueden caracterizar como de subsistencia, con una rutina alimentaria de una o dos comidas al día, siendo, además, comidas desequilibradas y descompensadas, altas, solamente, en productos calóricos, llegando incluso a atravesarse, en determinadas circunstancias, auténticos periodos de hambre o de escasez diaria de alimentos. Las economías migratorias, en esta línea, aparecen como economías de sobrevivencia, hechas o construidas a partir de compras pequeñas y escasas, de despensas mínimas que se estiran y se comparten, de pequeños prestamos, de incertidumbres de ingresos, de, en definitiva, circunstancias económicas que se instalan en esa eterna condición popular que tiene que ver con el vivir, económicamente, al día. En este sentido, es necesario subrayar, como durante deter- minados periodos de tiempo, muchos trabajadores inmigrantes ecuatorianos necesitan acudir a las redes sociales de atención primaria, principalmente de carácter privado, con el fin de completar y garantizar algunas de sus necesidades básicas en los países de destino; alimentos, transporte, ropa, salud, educación, etc.

Segundo, por una situación residencial degrada$\mathrm{da}$, donde la figura de los alojamientos de aglomeración se ha convertido en un rasgo social habitual entre la migración laboral ecuatoriana en estos años. Los trabajadores inmigrantes, en líneas generales, han "heredado" a precios de alquiler o de compra altos, en ocasiones muy por encima de sus salarios netos medios, un parque residencial precario que tradicionalmente había pertenecido a los sectores populares de la sociedad madrileña. Viviendas envejecidas $\mathrm{y}$, en múltiples ocasiones, en mal estado lo que suele conllevar la existencia de estructuras e instalaciones básicas deterioradas.

Una situación de debilidad residencial que es el resultado tanto de los precios inmobiliarios altos en el contexto español como de la debilidad social, jurídica y laboral de los migrantes. Un panorama que ha conducido, finalmente, al crecimiento de situaciones de fuerte precariedad en el alojamiento. Así, es habitual constatar entre la migración ecuatoriana en Madrid la existencia de pisos y habitaciones sobreocupados donde se agrupan y, en algunos casos, se hacinan un número elevado de familias y trabajadores inmigrantes. Pisos y habitaciones donde se constata la existencia de fuertes cadenas de subarrendamiento que terminan utilizando, ocupando y rentando todos los metros cuadrados y espacios habitables de la casa, incluyendo los espacios comunes. De esta forma, casas, cuartos, camas, e incluso colchones y sofás, entran a formar parte de estas cadenas de arrendamiento y subarrendamiento, generando una situación de sobre-ocupación que, finalmente, termina por afectar a las condiciones de vida diarias, especialmente a la intimidad y al descanso de quienes las habitan. Terminan, pues, generando procesos no solo de deterioro residencial sino también de fuerte desgaste personal y anímico entre unos trabajadores inmigrantes que, como se ha comentado anteriormente, combinan, habitualmente, esta situación de precariedad residencial con ritmos de trabajo intensivos y exigentes. Una combinación, a su vez, que termina construyendo cadenas de vida 
diaria sacrificadas, que termina, por tanto, extenuando física y mentalmente a muchos trabajadores inmigrantes y quebrando sus necesidades de descanso y reposición. Alojamientos urbanos, en definitiva, que, por momentos, si uno hace un ejercicio metafórico, pudieran recordar a los barracones rurales de los trabajadores jornaleros presentes en los espacios rurales aunque, en este caso, levantados, incrustados, al interior de los espacios urbanos. Barracones, pues, o zonas de vivienda francas, "construidas" para trabajadores deslocalizados en condiciones de precariedad en el interior del espacio urbano. Al tiempo, junto a estas condiciones de alojamientos de aglomeración, han ido apareciendo otras situaciones residenciales que aún manteniéndose dentro de condiciones de precariedad, han significado mejoras en la situación de vivienda de los migrantes ecuatorianos como, por ejemplo, aquellas familias que lograron acceder al alquiler de un piso y subarriendan o comparten los gastos de la casa, exclusivamente con familiares o con otra familia de amigos o conocidos, lo que les permite escapar de la situación de vulnerabilidad anterior.

Tercero, una situación de fuerte vulnerabilidad jurídica, que no solo les condena a presentarse de forma debilitada en el mercado de trabajo, en el mercado de vivienda o en la ventanilla de los servicios y prestaciones sociales sino que, al tiempo, genera una condición de ciudadanía vulnerable que precariza de forma recurrente sus horizontes vitales. Los trabajadores ecuatorianos, plenamente demandados e incorporados en la economía española, cuentan, de esta forma, con un estatuto jurídico inseguro y precario que no solo empobrece sus economías y su trabajo, al vulnerabilizar su acceso al mercado laboral sino que, también, debilita sus proyectos vitales, situándoles en una situación prolongada de interinidad en la sociedad y en la economía española. Un estatuto jurídico, resbaladizo y reversible, que se convierte en una carga más sobre la migración laboral que debe hacer frente, habitualmente, a un intrincado proceso de regularización. Un estatuto, pues, que, en última instancia, garantiza la aparición de condiciones de precariedad económica, laboral, residencial, familiar, etc.

Por último, es necesario destacar la existencia de un ambiente o una atmósfera psicosocial áspera o dura en torno a los migrantes ecuatorianos y, en general, en torno a la condición inmigrante. Atmósfera que tiene que ver no solo con los ritmos duros de vida y trabajo en España, donde, generalmente, el tiempo de la vida queda subsumido en el tiempo de trabajo sino, también, con otros factores de tipo sociocultural y afectivo: el extrañamiento frente a un país de acogida con unos códigos y unas formas sociales de ser diferentes, la nostalgia de Quito, Guayaquil, Cuenca, Loja y en general, "de la tierra de uno", la presencia de una fuerte carga étnica negativa acerca de la condición inmigrante, carga que se impone y pesa en los hombros de cada migrante concreto, la sensación de desclasamiento con respecto a su país de origen, de haber pasado a convertirse en una categoría social débil y estereotipada, como "los últimos" de la sociedad de acogida, etc. Una atmósfera psicosocial y cultural que aparece como una carga sobre los migrantes y que ayuda, en ocasiones, a recrudecer o endurecer, aún más, sus condiciones de vida en la sociedad de acogida.

Una nueva precariedad étnica, en el caso de los ecuatorianos, que aparece, pues, como una situación de incertidumbre económica, laboral y residencial. Incertidumbre e inseguridad que se instala como eje estructurador de los proyectos, las economías y los tiempos vitales de la migración laboral. Una situación social precarizada que, en última instancia, muestra el proceso de crecimiento de una franja social de trabajadores inmigrantes deslocalizados con condiciones de reproducción recortadas, estrechadas, en el marco actual de las economías de los países desarrollados. Una condición social vulnerable que, en múltiples ocasiones, termina construyendo espacios vitales marcados por el desgaste personal $\mathrm{y}$, directamente, por el sufrimiento. Una situación está que, por momentos, recuerda a ese estado de desdicha originado por una condición social, material y laboral, degradada y devaluada semejante a la que describe Simone Weil en los obreros franceses incorporados en la cadena de montaje (Weil, 1998). Una desdicha de origen social, como sufrimiento ligado a una condición social, que aparece, de forma recurrente, como algo visible y contante en los relatos de los migrantes ecuatorianos acerca de estos primeros años de migración laboral en España, ligada, por tanto, a las condiciones de precariedad étnica descritas en este apartado. 


\section{SEGUNDA PARTE \\ LAS CAUSAS; LOS ORÍGENES ECONÓMICOS, SOCIALES Y ÉTNICOS \\ DE LA NUEVA PRECARIEDAD INMIGRANTE}

La cuestión central en este apartado, una vez vistos y determinados algunos de los rasgos y coordenadas fundamentales de la precariedad inmigrante en las sociedades receptoras, es abordar el contexto social y estructural en el que surge y se crea esa precariedad étnica. La cuestión es, por tanto, indagar en los procesos económicos y sociales que están implicados en la creación y conformación de este nuevo espacio social precarizado de trabajadores inmigrantes al interior de las estructuras sociales de los países desarrollados.

Una cuestión que pasa por analizar, al menos, dos frentes o causas últimas diferentes. En primer lugar, es necesario analizar el actual proceso de reestructuración económica global que han sufrido las economías desarrolladas en las últimas décadas, dado que tal fenómeno se ha convertido en un agente central del proceso de ascenso y consolidación de un estrato social étnico, formado por población inmigrante procedente de países en desarrollo, con condiciones de vida y trabajo precarizadas. En segundo lugar, es necesario analizar los llamados factores sociales, esto es, los otros factores de género, etnia, clase, institucionales, etc.-, ya que, también, están en el origen del surgimiento de una condición social inmigrante deteriorada y vulnerable en las economías desarrolladas. Se trata, pues, de indagar, no solo en los procesos económicos estructurales de carácter general que están detrás de la formación de condiciones de precariedad entre los trabajadores inmigrantes, sino, también, y de forma especial, en aquellos procesos sociales que terminan fabrican$d o$ condiciones sociales de vulnerabilidad sobre las que, además, se construye y garantiza el suministro continuado de trabajo precario. Se trata, pues, en definitiva, de buscar las fuentes económicas y sociales de la precariedad y, en este caso, de la nueva precariedad étnica, recurriendo, nuevamente, a ese camino de ida y vuelta clásico de la sociología que va desde los contextos productivos a los contextos comunitarios, de la fábrica a la comunidad y retorna con el fin de ligar ambos en una sola explicación.

\subsection{El papel de la reestructuración económi- ca y social en la génesis y consolidación de la nueva precariedad étnica}

La cuestión central en este apartado, es buscar y establecer las conexiones causales existentes entre las condiciones de vida y trabajo deterioradas de los trabajadores inmigrantes y el proceso de reestructuración económica en curso en los países desarrollados, al menos, desde finales de los años 70'. De seguir, pues, si se quiere, el rastro de esa precariedad étnica hasta encontrar sus causas en la estructura económica y productiva actual. Una senda de investigación que lleva, necesariamente, a poner de manifiesto el papel activo que la dinámica económica de los países de origen tiene en la movilización e incorporación de trabajadores inmigrantes, frente a aquellas visiones estandarizadas que, en la actualidad, tienden a minimizar y eclipsar el papel que dichas dinámicas tienen en la configuración de los flujos migratorios, subrayando, de forma prácticamente unilateral, los procesos de crisis y subdesarrollo económico de los países periféricos como únicas causas, convirtiéndolos, así, en el discurso y en las políticas, en las auténticas y únicas fábricas de la migración laboral internacional (Sassen, 1988; Pedreño y García Borrego, 2005 y Castles y Miller, 2003).

Los países desarrollados viene sufriendo en las últimas décadas, una intensa dinámica de reestructuración económica provocada por el proceso de ajuste a las nuevas condiciones de competitividad y rentabilidad económica que ha impuesto el actual proceso de globalización. Aunque no es este el lugar para profundizar en los perfiles centrales de dicho proceso de reestructuración, si es necesario destacar y apuntar, brevemente, algunos de sus rasgos centrales, ya que ayudan a explicar y caracterizar los actuales flujos migratorios internacionales y la aparición de nuevas condiciones de precariedad étnica en las sociedades de acogida. En este sentido, algunos de los ejes claves del ajuste económico actual (Sassen, 1988; San Miguel, 2000; Castillo, 2002; Gallino, 2002 y Pedreño y García Borrego, 2005) serían los siguientes:

Antes de nada, la reestructuración ha pasado por una intensa dinámica de vaciado productivo de las grandes empresas comerciales, especialmente las de carácter transnacional, cuya contraparte ha sido, no 
tanto la automatización, como un creciente proceso de descentralización, subcontratación y deslocalización de la producción y el trabajo, sobre todo, de todas aquellas fases de trabajo que tienen que ver con la elaboración directa de bienes y servicios.

Como consecuencia de lo anterior se ha producido la consolidación de una "nueva" estructura económica basada en cadenas productivas de empresas, centros de trabajo, subcontratas y trabajadores, que aparecen dispersas y fragmentadas a lo largo y ancho del territorio y, al mismo tiempo, articuladas entre sí en los mismos procesos productivos. Cadenas productivas en estado fluido que incorporan y "ensamblan" en los mismos procesos de elaboración de bienes y servicios, y, por tanto, en los mismos procesos de obtención de rentabilidad, todos esos heterogéneos eslabones de producción y trabajo, incluyendo, por supuesto, la producción y el trabajo informal de talleres sumergidos, trabajadores no contratados y hogares particulares..$^{10}$ Un proceso de transformación económica, por tanto, que aúna, al tiempo, una profunda división y segmentación del trabajo manufacturero a lo largo y ancho de esos núcleos de empresas, talleres y trabajadores descentralizados, y una profunda articulación de dichos retales de producción, en las mismas cadenas de elaboración y de valor. Una estructura productiva que aparece, hoy, como la nueva fábrica fluida y global, el nuevo espacio productivo, descentralizado y segmentado, donde se elaboran los bienes y servicios de nuestras sociedades.

Un proceso de reestructuración que ha generado, al tiempo, nuevas dinámicas de segmentación y polarización económicas y laborales al interior de la industria y los servicios actuales. Cuestión que es visible no solo en el sector servicios, donde existe una creciente división entre el denominado terciario avanzado, ligado a núcleos empresariales comerciales y financieros, y compuesto de servicios profesionales especializados, de altas cualificaciones y rentas salariales, y los llamados servicios de bajos salarios, un sector de servicios obrero o manual degradado que se caracteriza por sus condiciones y rentas de trabajo bajas. Sino también, y de forma significativa, al interior de las cadenas de peque- ñas y medianas empresas que componen la nueva manufactura fluida, donde, se produce, no solo una creciente desigualdad entre el capital comercial y el productivo, en favor del primero, sino también, fuertes asimetrías laborales y productivas entre los diversos segmentos de producción que forman la actual manufactura descentralizada.

Una manufactura de bienes y servicios, dispersa, fluida, ligera, segmentada que, finalmente, ha creado, un intenso proceso de informalización del trabajo manual asalariado, convirtiéndose, de esta forma, y por la vía de reducir y flexibilizar los costes salariales, en un núcleo fundamental de las actuales estrategias de competitividad y rentabilidad económica. Cadenas productivas en estado fluido, pues, donde, progresivamente, han ido aflorando y emergiendo relaciones laborales precarias, esto es, polos de trabajo obrero, manual, caracterizados por la aglomeración de trabajo barato, flexible e intensificado, ligado a las diversas actividades de elaboración directa de bienes y servicios, y que aparece a lo largo $\mathrm{y}$, especialmente, al final de las procesos actuales de descentralización y externalización económica y empresarial. En este sentido, la actual reestructuración económica se ha convertido en un movimiento de intensa precarización de categorías crecientes de trabajo asalariado y, al tiempo, en un proceso productivo que generaba una fuerte, creciente y sostenida demanda de trabajo barato y flexible. Un proceso de reestructuración e informalización de las relaciones laborales que, en el caso español, fue aun más pronunciado y necesario dado que, desde finales de los años ochenta, y especialmente en la última década de expansión económica, se optó por un modelo y un patrón de crecimiento basado en sectores de baja productividad e intensivos en mano de obra. Sectores, pues, donde el proceso de externalización y la presencia de trabajo barato y flexible se convirtieron en un requisito estructural de sus dinámicas de competitividad y rentabilidad global.

Finalmente, es necesario añadir que junto a este proceso de reestructuración económica, se dio, al tiempo, un formidable proceso de transformación social, íntimamente ligado al anterior, que se convirtió, también, en un factor explicativo crucial del

${ }^{10}$ Para profundizar en este juego de lo formal y lo informal y en la profunda articulación productiva de ambos, ver: (Sassen, 1988; Arias, 1998; Castillo, 1999 y 2002 y Gallino, 2002). 
actual movimiento migratorio internacional hacia las economías desarrolladas $\mathrm{y}$, en concreto, hacia España. Se trata de la emergencia de unas nuevas clases medias profesionales urbanas ocupadas en los sectores de servicios avanzados del sector privado y de la administración del estado, y junto a ello, el ascenso y consolidación de unos nuevos estilos de vida, trabajo y ocio en los espacios urbanos; estilos marcados, fundamentalmente, por la incorporación de la mujer al mercado de trabajo, el acceso a rentas salariales más elevadas y la emergencia de pautas de ocio y tiempo libre diferentes. Un proceso social, sólidamente imbricada en el proceso de reestructuración económica, que ha terminado creando nuevas necesidades domésticas, laborales y de ocio y, finalmente, una creciente y sostenida demanda de trabajo asalariado, barato y abundante, relacionada con ocupaciones manuales de servicios en sectores como la industria del ocio, la distribución, la hostelería, los servicios comunitarios y, especialmente, el sector de servicios domésticos, convertido, este último, en un auténtico motor de arrastre de la migración internacional laboral femenina y, específicamente, ecuatoriana en el contexto madrileño y español. ${ }^{11}$

Una reestructuración económica y social, en definitiva, que terminó generando una fuerte y sostenida demanda de trabajo manual desregulado, barato y flexible, ligada a esas nuevas cadenas de empresas y centros de trabajo descentralizados, que en el caso español, además, eran altamente intensivos en trabajo asalariado, y al crecimiento de las nuevas necesidades de trabajo recreadas por los nuevos estilos de vida, trabajo y ocio de las emergentes clases medias profesionales. Una formidable demanda de trabajo barato y flexible que, en un primer momento, se nutrió de grupos sociales tradicionalmente vulnerables del mercado de trabajo español como mujeres y jóvenes procedentes, sobre todo, de los sectores populares, pero que, finalmente, y conforme los procesos económicos en curso se intensificaron, terminó transcendiendo el marco del mercado de trabajo nativo y fue, paulatinamente, entrando en contacto, enganchando, con flujos y redes migratorias internacionales, ya prexistentes, y en ese proceso, convocando, movilizando, arrastrando y reclutando a mano de obra inmigrante, precisamente, hacia aquellos sectores de producción y trabajo ya degradados y descentralizados que la restructuración había ido creando en la nueva economía productiva. ${ }^{12}$

Se puede decir, por tanto, como conclusión que la reestructuración económica y social llevada a cabo por los países desarrollados en las tres últimas décadas y, en concreto en la economía española, ligada al actual proceso de globalización, se ha convertido en un agente estructural central a la hora de comprender, no solo el formidable ciclo migratorio internacional de carácter laboral que ha tenido España en las dos últimas décadas, esto es, a la hora de comprender el proceso que convocó y movilizó la deslocalización y posterior incorporación de trabajadores inmigrantes, baratos y flexibles a las sociedades de destino sino, sobre todo, a la hora de comprender la progresiva formación de un segmento de trabajo étnico, degradado y flexible, al interior de sus economías y mercados de trabajo y, a raíz de ello, la sedimentación de un bloque social precarizado y etno-estratificado al interior de sus estructuras sociales. Un segmento social etno-estratificado, una nueva precariedad étnica, que es, de esta forma y en gran medida, el resultado estructural de las opciones de crecimiento y ajuste productivo seguidas por los países desarrollados en los últimos años al hilo del proceso de globalización económica.

\footnotetext{
${ }^{11}$ Es necesario explicitar que dicha transformación social está muy ligada a la mayor incorporación de la mujer al empleo asalariado y al hecho de que las nuevas necesidades domésticas planteadas se hayan cubierto, finalmente, por procesos de mantenimiento y reproducción de un reparto desigual de las tareas del hogar basado en códigos de género y por el recurso al trabajo externo femenino a la unidad familiar. Una situación que, entre otras razones, es debida a la existencia de escasos apoyos en términos de gasto social dado el carácter familista que tiene el estado del bienestar español. Para analizar en profundidad este proceso de transformación social y sus vinculaciones con la migración laboral internacional tal y como se ha producido en España, algunas referencias imprescindibles serían (Herranz 1997; Martínez Veiga, 1997; Oso, 1998; Parella, 2001; Colectivo IOE, 2001; Herrera, 2007 y Martínez Buján, 2009).

${ }^{12}$ Obviamente, se trata, generalmente, de trabajadores y familias que a tenor de las precarias condiciones políticas y económicas existentes en sus contextos de origen, y de las grandes desigualdades existentes en términos de renta en la economía mundial, estaban disponibles para movilizarse y emprender un proceso migratorio laboral internacional, disponibles, por tanto, como mano de obra barata en la economía mundial.
} 


\subsection{Los factores "sociales": género, clase y etnia en la génesis de la nueva precariedad étnica}

Un segundo frente en el análisis de las condiciones de precariedad de los trabajadores inmigrantes tiene que ver, no ya con los procesos económicos estructurales, variables clásicas en el análisis de los procesos de empobrecimiento y estratificación social sino, más bien, con una serie de procesos y factores sociales de clase, género, de etnia, etc., cuyo centro de gravedad se sitúa en el espacio socio-comunitario, en, si se quiere, el denominado fuera de la fábrica de los estudios clásicos de la sociología del trabajo (Lahera, 1998 y Castillo, 2002). Procesos sociales que se transforman en factores explicativos esenciales al convertirse en el sustrato social e ideológico sobre el que se asientan y consolidan diversas formas de vulnerabilidad económica, social y laboral. Factores sociales, por tanto, que alientan, en última instancia, la formación de un bloque social de trabajadores extranjeros vulnerables y empobrecidos y por ello altamente disponibles para ocupar los empleos o salarios más baratos y flexibles de la estructura económica (Pedreño y García Borrego, 2005). En este apartado, por tanto, se pretende indagar en la base social de género, clase, etnia, etc. ${ }^{13}$ que está detrás de la emergencia y consolidación de un bloque social etno-estratificado en el seno de las estructuras sociales de los países desarrollados. Cinco, son los factores que se quieren destacar en esta línea:

En primer lugar, hay que hablar de la pobreza económica. Así, la pobreza que, generalmente, en los estudios del trabajo es pensada como el resultado de los procesos de degradación laboral se convierte, bajo el prisma de este análisis, también, en un vector explicativo más de las situaciones de precariedad laboral, dado que la vulnerabilidad económica de los migrantes laborales al penetrar en el mercado laboral se transforma, generalmente, en trabajo precario. De esta forma, las condiciones de pobreza y precariedad económica en las que se encuentran una parte significativa de los migrantes laborales en las sociedades de acogida se convierten, finalmente, en un factor de precariedad laboral, en un laberinto social y un lastre que urge y disciplina a los trabajadores inmigrantes en el mercado de trabajo, y que debilita sus relaciones laborales. Que urge, para trabajar en lo primero que se presente, y que disciplina, dentro ya del mercado de trabajo, para "aguantarse" en él, y así, "uno se aguanta porque uno está necesitado", ${ }^{14}$ para, por tanto, aceptar y soportar condiciones y ritmos de trabajo marcados por la desregulación, la intensificación, los bajos salarios, etc. El empobrecimiento de los migrantes en los países desarrollados se convierte, de esta forma, no solo en un retrato estático de su fragilidad social y económica o, si se quiere, en la derivada de su condición laboral sino, sobre todo, en un hilo analítico y causal que permite comprender su situación en el mercado de trabajo. Se convierte, pues, en el suelo económico movedizo y vulnerable sobre el que crece y se consolida el trabajo degradado y, en última instancia, se enraízan los procesos de etno-estratificación actuales en los países desarrollados.

El Género es un segundo factor social clave a la hora de analizar la creación de asimetrías económicas y laborales y, por tanto, a la hora de comprender los procesos de formación de un segmento social étnico precarizado y feminizado. Dos son las cuestiones que se quieren destacar, en este sentido:

En primer lugar, es necesario indagar en el género que se convierte en precariedad laboral; esto es, en todas aquellas categorías o representaciones asimétricas de género, impuestas sobre las mujeres inmigrantes y sus cualidades por el hecho de ser mujeres, que al ser recreadas y utilizadas en el mercado de trabajo terminan construyendo condiciones de trabajo vulnerables. Así, por ejemplo, en un sector como el doméstico, ampliamente precarizado y feminizado, se constata como las definiciones ideológicas acerca del trabajo femenino, esto es, un trabajo representado y pensado como tarea y salario complementario, ligado, de forma natural, al ámbito doméstico y, por tanto, apartado del marco regulatorio laboral normalizado y un trabajo imaginado como ligero, sin apenas desgaste y calificación, terminan

\footnotetext{
${ }^{13}$ Estos factores se presentan por separado por razones expositivas, pero en la realidad social aparecen fuertemente enhebrados entre sí, componiendo esa raigambre social y sociológica sobre la que se asientan los procesos de precarización laboral y social.

${ }^{14}$ Así lo explicaba durante el trabajo de campo un inmigrante ecuatoriano procedente de Cayambe (Quito).
} 
transformándose en una fuerza social que crea y legitima condiciones laborales degradadas, en, por tanto, trabajos extenuantes de bajos salarios que juntan en una misma jornada laboral todo tipo de tareas del hogar, o trabajos profundamente desregulados en términos de relaciones laborales, etc. Se trata, en definitiva, de indagar en representaciones de género acerca del trabajo y los roles femeninos que nacidas, generalmente, en procesos de socialización comunitarios son utilizadas, manejadas y recreadas en el ámbito laboral para legitimar, justificar y crear condiciones de trabajo precarias entre las mujeres inmigrantes; para crear, por tanto, una precariedad laboral y económica con una sólida raigambre de género (Borderías, 1991; Oso, 1998).

En segundo lugar, es necesario tener en cuenta el papel del género en la configuración y el desenvolvimiento del proceso migratorio. El protagonismo femenino en la actual migración internacional, y latinoamericana, es ya un lugar común en la literatura especializada. Un protagonismo, que parece generar efectos positivos, al estimular, al mismo tiempo, una mayor autonomía económica y familiar de las mujeres migrantes, dado su papel preminente en las cadenas migratorias familiares y en el ámbito de las remesas y, también, en ocasiones, procesos de distanciamiento y ruptura frente a los propios códigos de género adquiridos en el ámbito familiar y comunitario de origen (Parella, 2000 y NybergSørensen, 2004). Ahora bien, aunque es necesario destacar estos factores positivos aparejados a la migración femenina, es preciso, también, subrayar el papel que el género desempeña en la creación de asimetrías sociales y laborales al interior de dicha migración. En esta línea, la investigación etnográfica realizada con mujeres ecuatorianas vino a mostrar cuestiones que hablan de la proyección y reproducción de desigualdades de género en el seno de las cadenas migratorias internacionales (Herrera, 2007). Por ejemplo, la utilización de las mujeres migrantes como mano de obra familiar, esto es, la proyección de categorías de género en la migración internacional que conducen a la utilización y supeditación del trabajo, y del propio proyecto migratorio, de las mujeres inmigrantes al proyecto familiar. $\mathrm{O}$ la persistencia de roles asimétricos de género al interior de las familias reagrupadas en Madrid, roles que se reflejan en una estricta división del trabajo familiar donde las cargas y tareas domésticas vuelven a caer sobre la espalda de las mujeres migrantes. Una situación que se agrava, aún más si cabe, por el hecho de que, generalmente, las mujeres inmigrantes están incorporadas intensamente al mercado de trabajo, lo que conlleva, finalmente, la aparición de jornadas laborales extenuantes donde el continuum trabajo doméstico-trabajo asalariado fuera del hogar se confunden y se prolongan mutuamente.

Se trata de asumir, en resumen, que una veta central de los procesos de etno-estratificación actuales de la población inmigrante en las economías desarrolladas está compuesta por procesos asimétricos de género, procesos que cristalizan en la aparición de condiciones de vida y trabajo aún más degradadas entre las mujeres migrantes. Una realidad que empuja a investigar e incorporar en la investigación herramientas teóricas de género que permitan hacer visibles esas asimetrías ceñidas a la realidad de las mujeres migrantes.

En tercer lugar es necesario subrayar el papel de la etnicidad como fuente social clave de las condiciones de precariedad de los inmigrantes en los países desarrollados. La etnicidad, pues, como fuente de los diversos procesos de desigualdad económica, social y laboral que afectan a los inmigrantes en los países de acogida. Algo que obliga a ponderar las relaciones existentes entre las representaciones étnicas que sobre los inmigrantes se elaboran y difunden socialmente, y los procesos de formación de un segmento social etno-estratificado y precarizado en el seno de los países desarrollados. ${ }^{15}$ Tres son las cuestiones que se quieren destacar en esta línea de trabajo:

En primer lugar, hay que hablar de la construcción de una especie de inmigrante soñado ${ }^{16}$ de rasgos netamente negativos, que se superpone sobre la realidad real de la población inmigrante. Se trata de la elaboración por parte de la sociedad receptora de una representación acerca de los trabajadores inmi-

\footnotetext{
${ }^{15}$ Aunque la etnicidad presenta otras consecuencias, más invisibles, relacionadas con los efectos que la violencia simbólica ejerce sobre el ánimo y el cuerpo de los trabajadores inmigrantes.

${ }^{16}$ La figura está directamente entresacada de la idea de El Obrero Soñado de Sierra (1990).
} 
grantes ideológica y cargada de rasgos sociales negativos. Atributos étnicos, distorsionados y falsos, que, finalmente, al proyectarse sobre los propios trabajadores inmigrantes, en un proceso que desfigura su realidad social, se convierten en la base argumental sobre la que se despliegan y legitiman prácticas $\mathrm{y}$ estrategias de desregulación de sus relaciones y condiciones de vida y trabajo. Un inmigrante soña$d o$, pues, que al ser utilizado y movilizado en los espacios laborales, productivos y sociales, termina legitimando, sosteniendo y generando procesos de etno-estratificación social.

Así, la generación y reproducción reiterada y, en ocasiones, interesada de categorías étnicas negativas acerca de los trabajadores inmigrantes; su representación, pues, como una condición social específica y deteriorada; una población amenazante, peligrosa y subdesarrollada, y, al mismo tiempo, como una condición laboral atrasada, dócil, y premoderna; una especie de ídolo tercermundista, pobre y paterizado que transita entre el hambre, la ignorancia y la barbarie; se convierte, en ocasiones, en el factor clave que legitima y consolida las condiciones de precariedad de los trabajadores inmigrantes en el mercado de trabajo y en los espacios comunitarios. Un camino, pues, por el que la etnicidad, en tanto representación ideológica negativa acerca de los migrantes, se transforma en fuente de vulnerabilidad social y laboral en los países desarrollados. ${ }^{17}$ Así, por ejemplo, durante la investigación de campo realizada se encontró que, en muchas de las relaciones laborales de los ecuatorianos, su trabajo era representado como un don del empleador o, en su defecto, de la sociedad receptora hacia una población atrasada y empobrecida; "como si fuéramos muertos de hambre". Un don que, finalmente, generaba o, sencillamente, legitimaba una serie de obligaciones laborales excesivas por parte del inmigrante; disciplina, sacrificio, tareas y jornadas desmedidas, salarios bajos y, en general, aceptación de las condiciones laborales, fueran estas las que fueran. Un estigma u orden simbólico negativo que, no solo atraviesa el mercado de trabajo, legitimando o recreando condiciones laborales devaluadas, sino que, al tiempo, consolida y justifica condiciones de vida precarias y degradadas como, por ejemplo, ocurre en el caso de la vivienda donde el discurso étnico negativo acaba legitimando la vulnerabilidad o la segregación residencial y territorial (Pedreño, 2007a). Una carga étnica negativa, además, que no solo justifica la precariedad sino que, en última instancia, apantalla la realidad migratoria al enmascarar, por ejemplo, la fuerte dependencia que tiene la economía y la sociedad de acogida de los jornales y salarios flexibles de los inmigrantes.

De esta forma, la construcción de un discurso étnico negativo sobre los inmigrantes que los representa como una figura social estigmatizada y descalificada; la elaboración, en resumen, de un inmigrante soñado cargado de atributos negativos, termina deteriorando sus condiciones de vida y trabajo y convirtiéndose, así, en un pilar esencial para comprender la nueva precariedad étnica. Un inmigrante soñado, pues, que no es solo un catálogo de prejuicios o un sencillo imaginario colectivo de raíces racistas sino que, al tiempo, es una construcción étnica con fuerza social, esto es, una representación devaluada que, finalmente, penetra la realidad y genera violencia simbólica y material sobre la población inmigrante, eclipsando y justificando, de paso, determinados intereses y necesidades de las sociedades receptoras.

Un caudal étnico negativo que, además, transciende la propia figura de los migrantes extracomunitarios para abarcar y estigmatizar su propia realidad social y laboral. De tal forma, que el capital simbólico devaluado proyectado, vertido, sobre los propios trabajadores inmigrantes desde el imaginario colectivo termina por ceñirse, finalmente, sobre la propia realidad social que habitan, configurando y adjetivando, en términos negativos, sus espacios de vida y trabajo. Devaluando, pues, ya no la condición social inmigrante, sino la propia realidad social en la que viven y trabajan, y con ello determinadas categorías ocupacionales o sectores productivos, o determinados espacios territoriales, o determinados servicios sociales y educativos. Un círculo ideológico, étnico, que termina explicando y legitimando la persistencia de espacios sociales y segmentos laborales de población inmigrante marcados por la precariedad.

En segundo lugar, hay que hablar del papel de la etnicidad en la construcción de enclaves laborales

\footnotetext{
${ }^{17}$ El apéndice final de Castles y Kosack, (1984) sobre racismo estructural, es una excelente referencia en este sentido.
} 
étnicos (Castles y Miller, 2004 y Pedreño, 2007a). Se trata de un proceso de atribución de rasgos étnicos específicos a un determinado colectivo de trabajadores inmigrantes cuyo fin es incorporar y fijar a esos trabajadores en unas determinadas tareas y ocupaciones, generalmente, precarias. Se trata, pues, de movilizar y fijar a una determinada población inmigrante en segmentos de trabajo desregulado mediante la atribución de rasgos étnicos concretos que, al mismo tiempo, justifican su presencia en dichos puestos de trabajo degradados y su ausencia de otros sectores u ocupaciones más valoradas. Unos enclaves étnicos de trabajo degradado que, además, en mercados abiertos y globalizados se convierten en un eje competitivo fundamental de determinados sectores intensivos en trabajo, al garantizar el suministro continuado de trabajadores baratos y flexibles.

En este sentido, lo que se plantea es indagar en el papel que juega la etnicidad en contextos y procesos laborales determinados. En esta línea, habría que reconstruir, para cada caso, las categorías, estereotipos y marcadores étnicos que se manejan en las situaciones concretas de trabajo, preguntándose acerca de quién los maneja, incluyendo a los propios inmigrantes, y con qué fines y objetivos se utilizan. Se trata de una línea de trabajo que aúna migración, etnicidad y precariedad laboral, donde "estalla" la diversidad y la complejidad de los casos concretos, y donde, en ocasiones, aunque con mucha menos fuerza social los propios trabajadores inmigrantes aparecen involucrados en ese juego de marcadores étnicos, utilizando y reproduciendo determinadas categorías, acerca de sí mismos y de otros colectivos, en beneficio propio y, no solo, como víctimas pasivas de operaciones de definición ideológica externas. Así, por ejemplo, en el caso de las mujeres ecuatorianas que trabajan en el servicio doméstico madrileño, se encontró durante la investigación que las empleadoras autóctonas manejaban atributos étnicos positivos y negativos con respecto a las empleadas ecuatorianas. De un lado, atribuían a estas, como colectivo, una cierta cualidad positiva y diferenciadora para el sector, ya que eran representadas como trabajadoras más afectivas en el desempeño del trabajo, ya que eran, por tanto, mujeres más cariñosas que cuidaban con mayor atención e implicación emocional a niños y mayores. Un bagaje laboral étnico este que justificaba su incorporación laboral al sector, legitimando, en ocasiones, un proceso de sustitución de las empleadas domésticas anteriores. Al tiempo, esas mismas empleadoras manejaban representaciones étnicas negativas sobre las trabajadoras latinoamericanas y ecuatorianas, caracterizándolas, por ejemplo, como lentas, "cambionas" y poco operativas y diligentes en las tareas domésticas, "están siempre con él ahorita”. Una representación que justificaba la intervención de la empleadora en términos de intensificación del trabajo o, por ejemplo, legitimaba el pago de salarios domésticos bajos. De esta forma, un atributo étnico, ideológico y negativo, sobre las mujeres ecuatorianas, construido en torno a la imagen del ahorita, ${ }^{18}$ se convertía, finalmente, en la fuerza que justificaba, al tiempo, los bajos salarios, la intensificación de sus ritmos de trabajo en los hogares y la persistencia de modelos laborales donde la necesidad de control y vigilancia de la empleadoracapataz estaba perfectamente legitimada. El ahorita como descriptor étnico de la actitud laboral de las mujeres ecuatorianas terminaba, así, justificando esa precariedad laboral, aun en casos donde la realidad presentaba jornadas manchesterianas de doce o catorce horas diarias de trabajo constante, seis días a la semana. Finalmente, y al mismo tiempo que esto sucedía, las propias trabajadoras ecuatorianas, siendo plenamente conscientes de la irrealidad de esas categorías e incluso, en ocasiones, del hecho de que su aparente parsimonia era, solo, una estrategia de resistencia frente a los excesos laborales de sus empleadores, utilizaban, ellas mismas, a su favor, esos marcadores étnicos en sus relaciones laborales en el sector doméstico. Así, en ocasiones, con el fin de conseguir empleo y penetrar en el mercado de trabajo diferenciándose de otras trabajadoras, nativas e inmigrantes, las ecuatorianas aludían a la cuestión de su supuesta cualidad afectiva, haciéndola valer frente a otras trabajadoras del sector o, incluso, como argumento de resistencia frente a la imposición de ritmos de trabajo más intensificados.

\footnotetext{
${ }^{18}$ Expresión común en determinados contextos latinoamericanos que se impone como estereotipo sobre todo el colectivo, y que viene a definir una actitud laboral de baja intensidad. Algo que debe ser transformado por la tenaz y directa intervención de la empleadora.
} 
Por último, es necesario comentar la existencia de categorías sociales y étnicas propias al interior de las redes sociales migratorias. Así, los códigos y representaciones étnicas y sociales aprehendidos e incorporados por los propios inmigrantes en sus países de origen se reproducen en los países de acogida, convirtiéndose en mecanismos que provocan cortes y asimetrías entre las propias redes sociales migratorias que terminan construyendo procesos de precarización social y laboral. De esta forma, se constató durante la investigación que los migrantes ecuatorianos reproducían sus códigos étnicos asimétricos de origen en la realidad madrileña, ajustando en base a ellos, por ejemplo, el acceso o la posición desigual de sus compatriotas en determinados bienes sociales; trabajo, redes de reclutamiento laboral, alojamiento, información, etc.

La etnicidad, de esta forma, se convierte en una categoría clave para entender las raíces sociales de la precariedad laboral y económica de los migrantes en los países desarrollados. Una categoría lábil y resbaladiza pero que, sin embargo, opera con una fuerza social decisiva en la construcción de un segmento social inmigrante vulnerable y precario.

Para afrontar el cuarto factor habría que hablar del papel que han cumplido los factores políticoinstitucionales a la hora de moldear y generar las condiciones de precariedad existentes entre los trabajadores inmigrantes en las sociedades receptoras $y$, en concreto, el papel que tanto la normativa de extranjería, como los sucesivas leyes de desregulación laboral han jugado en la consolidación de la nueva precariedad étnica. ${ }^{19}$ Se trataría, al mismo tiempo, de indagar en la existencia del llamado racismo institucional (Castles y Kosack, 1984), esto es, la existencia de una serie de prejuicios y representaciones negativas acerca de los migrantes, que aparecen como el sustrato ideológico que da cobertura y legitima el diseño de dispositivos institucionales y marcos jurídicos que, en múltiples ocasiones, terminan garantizando y apoyando la construcción de un amplio segmento de población trabajadora de origen inmigrante disciplinada, flexible y empobrecida en los países desarrollados.

No es este el espacio adecuado para profundizar en detalle en estos procesos político-institucionales, sirva, de todas formas, como ejemplo, el caso de la normativa de extranjería y la figura del trabajador inmigrante indocumentado generada por ella. La figura, por tanto, de un trabajador irregular presente en el mercado de trabajo y, al tiempo, ausente en el reconocimiento jurídico. Un trabajador, sin permisos legales reconocidos pero, y esa es la contradicción, convocado, demandado e incorporado de hecho en el mercado de trabajo, siendo, además, un eje clave de las actuales estrategias de competitividad empresarial. Un trabajador que, en estas circunstancias, termina viendo como la vulnerabilidad jurídica que diseña la ley se convierte, y es utilizada, como fuente de precariedad laboral y social en una economía como la española necesitada de trabajadores industriales y de servicios baratos. De esta forma, sobre esta ambigüedad de trabajadores que carecen de reconocimiento jurídico pero que, de hecho, son reclamados y están incorporados en el mercado de trabajo, se asienta una parte de la nueva precariedad laboral y económica de los migrantes en las sociedades desarrolladas. Y es, en este sentido, en el que se puede interpretar que la normativa de extranjería es, también, una fuente nutriente de las actuales condiciones de precariedad étnica en España. Una normativa y, en definitiva, una política migratoria, que se ha centrado más en actuar sobre el control de fronteras y en elaborar un estatuto jurídico de regularización restringido, que en actuar sobre las condiciones de trabajo y sobre el contexto socio-productivo en el que se incorporaba la migración, aquello que parece siempre ha sido el principal "efecto llamada" del actual flujo laboral internacional. ${ }^{20}$ Quizás, como se apunta desde la experiencia mexicana (Canales, 2002) la contradicción se resuelve si se piensa en la actuación política migratoria, tan restrictiva en los cauces formales de entrada, no como un freno de la migración internacional, sino como un gesto crucial hacia la audiencia política nativa o, en el peor de los casos, como un regulador del

\footnotetext{
${ }^{19}$ La referencia fundamental e imprescindible en este terreno es el trabajo de Lorenzo Cachón, (Cachón, 2006) Junto a este factor, específico del colectivo inmigrante, habría que indagar en el papel que la legislación laboral ha tenido en el proceso de flexibilización del mercado de trabajo. (Castillo, 2002)

${ }^{20} \mathrm{Como}$, por ejemplo regulando al alza determinados segmentos laborales como el sector doméstico.
} 
nivel adecuado de mano de obra inmigrante irregular, flexible y barata.

Por último, a la hora de caracterizar y comprender las condiciones de precariedad de los trabajadores inmigrantes en los países desarrollados, es necesario integrar en el análisis la dimensión transnacional que tienen sus proyectos migratorios.

La realidad social de los migrantes está atravesada, al menos, por dos contextos sociales diferentes, el de destino y el de origen. Y lo está, sobre todo, porque, habitualmente, los inmigrantes mantienen los vínculos y lazos sociales con sus familias y comunidades de origen formando parte, así, de hogares transnacionales. De esta forma, frente a una cierta representación de la migración internacional como un proceso social escindido que sucede, de forma univoca, o bien en el contexto de origen, o bien en el de destino, lo que se plantea es incorporar una perspectiva de análisis que tenga en cuenta las relaciones y prácticas transnacionales existentes entre los migrantes ecuatorianos y sus hogares y comunidades de origen, y los efectos que dichos vínculos activos tienen sobre sus condiciones de vida y trabajo en Madrid (Pries, 1998 y Nyberg-Sørensen, 2004). Se trata, en última instancia, de enhebrar a los trabajadores ecuatorianos en los grupos familiares y domésticos a los que pertenecen, considerando, así, sus hogares como hogares transnacionales donde uno, o más, de sus miembros viven y trabajan en el extranjero, e incorporando al análisis de la situación económica y laboral de los migrantes en los países de destino esta particularidad social. Se trata, pues, de reconstruir su proximidad social más allá de la distancia geográfica que les separa de sus contextos de origen. Dos son las cuestiones que se quieren destacar en esta línea.

Por un lado, asumir que para entender las condiciones de vida y trabajo de los inmigrantes en los países desarrollados es necesario tener en cuenta la situación socio-económica del hogar familiar en la comunidad de origen. Así, cuestiones como los procesos de empobrecimiento en origen o la posible dependencia de las remesas por parte los hogares familiares de partida, se convierten en factores, transnacionales, que operan con fuerza sobre la realidad social de los migrantes en destino y, de forma especial, en sus condiciones de vida y trabajo. Así, en múltiples ocasiones, la fuerza que, literalmente, empujaba a los ecuatorianos a aceptar condiciones de trabajo duras y extenuantes o, directamente, condiciones de fuerte explotación laboral o, en otro frente, la razón que explicaba los durísimos ajustes en partidas básicas del gasto que realizaban en Madrid, no era tanto su vulnerabilidad socio-económica en la sociedad de acogida sino, más bien, por ejemplo, la urgencia de enviar fondos al hogar familiar de origen, dependiente o necesitado de ellos, es decir, la situación socio-económica de la familia en el contexto de origen. Una necesidad o urgencia que, además, se actualiza, constantemente, con las llamadas y contactos habituales de los migrantes con sus familiares en origen, esto es, con el mantenimiento del contacto y los lazos transnacionales con su contexto social de partida. En definitiva, se trata de una precariedad socioeconómica ligada al contexto de origen que, finalmente, sobre el vínculo social de los migrantes se desterritorializa y transnacionaliza, actuando como una fuerza que vulnerabiliza sus condiciones de vida y trabajo en las sociedades receptoras. Una fuerza que, por ejemplo, ayuda a explicar el fuerte ajuste laboral y de gasto que los inmigrantes realizan en los países desarrollados con el objetivo de sustraer de la escasez, recursos para ser convertidos en remesa y salario familiar en el país de procedencia.

Un segundo factor, que tiene ver con esta especificidad transnacional de la precariedad laboral étnica en los países desarrollados es la cuestión de la inversión migratoria, esto es, el esfuerzo realizado en términos económicos, vitales y relacionales por parte de los migrantes y sus familias en el proyecto migratorio que les separa de sus contextos sociales de referencia. Una inversión, en forma de endeudamiento económico, proyecto vital, separación de pareja, hijos, parientes, abandono de referencias culturales cercanas, movilidad social descendente, etc., que se convierte, finalmente, en el empedrado social que, por caminos inesperados, termina quebrando sus condiciones de vida y trabajo en los contextos de acogida. Así, por ejemplo, durante la investigación se constató que la necesidad de recortar cuanto antes los tiempos de separación afectiva o, en general, la necesidad de capitalizar y justificar el esfuerzo y la inversión vital realizada con la inmigración, provocaba entre los ecuatorianos una cierta presión que les empujaba a convertir la mayor parte de su tiempo de vida en Madrid en tiempo de trabajo, o a aceptar y permanecer en trabajos profundamente devaluados a pesar de sentirse laboralmente explotados. 
Una inversión migratoria, pues, que remite a una realidad social transnacional que acaba convertida en un poderoso factor de vulnerabilidad y precariedad laboral y social en la sociedad de acogida.

Finalmente, a la hora de analizar las condiciones de precariedad étnica es necesario indagar en la presencia de marcos sociales y culturales transnacionales. Así, los trabajadores inmigrantes al incorporarse a las sociedades de acogida traen consigo marcos culturales propios, que, por ejemplo, incorporan valoraciones y evaluaciones sobre el trabajo y las condiciones de vida que terminan influyendo, decisivamente, en sus formas de interpretar y comportarse en la realidad social y laboral de los países desarrollados. Marcos, por tanto, que deben ser reconstruidos $\mathrm{y}$ tenidos en cuenta a la hora de evaluar sus opciones y sus condiciones de vida y trabajo en destino. En este sentido, por ejemplo, las experiencias pasadas y las valoraciones en torno a la mayor o menor dureza del trabajo, o al mayor o menor estatus social que concede de una actividad determinada, representan cuestiones que son interpretadas de forma diferente por las diferentes poblaciones inmigrantes y que influyen decisivamente en sus decisiones económicas y laborales, algo que surgió de forma recurrente en el trabajo de campo.

\section{CONCLUSIÓN \\ UN SEGMENTO SOCIAL ETNO- ESTRATIFICADO AL INTERIOR DE LA ESTRUCTURA SOCIAL ESPAÑOLA}

El fenómeno de la migración internacional laboral, tal y como se ha generado en la realidad española en las dos últimas décadas, ha provocado la emergencia y consolidación de una nueva precariedad étnica, y con ello, un intenso proceso de etno-estratificación al interior de la estructura social del país. Estamos, pues, ante la emergencia de un segmento social precarizado formado por trabajadores inmigrantes procedentes de países en desarrollo cuya configuración social se puede descomponer en dos frentes profundamente interrelacionados entre sí:
Por un lado, la aparición y estabilización de una nueva precariedad laboral étnica, construida en torno a la población inmigrante. ${ }^{21}$ Esto es, la presencia de un nutrido y creciente grupo de trabajadores inmigrantes que aparecen, como trabajo barato y flexible, al final de los actuales procesos de reestructuración económica y de subcontratación productiva de los países desarrollados. Un bloque de trabajadores que forman, por tanto, el eslabón productivo y laboral más precario y desregulado de las nuevas cadenas empresariales descentralizadas que, hoy, constituyen la estructura económica de los países desarrollados.

Una mano de obra global barata y flexible que, paulatinamente, fue convocada, reclutada e incorporada como trabajo asalariado precario en sectores productivos y empresariales de difícil deslocalización, como el segmento laboral de servicios manuales de bajos salarios. Pero, también, y esto es importante subrayarlo, para sectores de la nueva industria metropolitana descentralizada, aquel sector de fabricación degradado, que en ningún momento se deslocalizó al lejano sur, sino que, por el contrario se resituó, descentralizado, disperso, fragmentado y subcontratado en el espacio periférico de los países desarrollados, incorporando, para ser competitivo en términos de los actuales mercados globales, mano de obra inmigrante bajo la forma de trabajo obrero desregulado. Un proceso que, sin duda, añade nuevas complejidades a la actual división global del trabajo, tantas veces pensada de forma lineal.

Un caudal de trabajo migrante, barato e intensificado, que remite, finalmente, a la emergencia y consolidación de autenticas zonas francas de trabajo al interior de las economías desarrolladas, esto es, de zonas de trabajo asalariado en la industria y los servicios subcontratadas, desreguladas y abaratadas. Zonas de producción y trabajo francas "globalizadas" a partir de la presencia de trabajadores inmigrantes deslocalizados que, de alguna forma, plantean la emergencia de auténticos espacios laborales de maquila al interior de los países desarrollados, esto es, de segmentos productivos y ocupacionales degradados, confeccionados a partir de la presencia

\footnotetext{
${ }^{21}$ No se trata de un segmento de ocupaciones, empresas y sectores copado, exclusivamente, por trabajadores inmigrantes. En el mercado de trabajo español hay nativos desempeñando las mismas tareas y ocupaciones, y en los mismo sectores, que los trabajadores inmigrantes, lo que sucede, habitualmente, es que estos suelen hacerlo en peores condiciones laborales.
} 
abundante de trabajo precarizado, en este caso, a partir del reclutamiento y la presencia de migrantes laborales vulnerables y disponibles para esos puestos de trabajo. Un espacio laboral étnico y globalizado, pues, que constituye el engranaje más débil y empobrecido de las actuales dinámicas del capital comercial en los países desarrollados, aquel que hoy en día teje y desteje redes de producción y trabajo asimétricas en la nueva geometría variable de la globalización.

Un nuevo segmento laboral de obreros inmigrantes informalizados que emerge por debajo y dentro de la precariedad laboral y social nativa generada desde la segunda mitad de los años ochenta en el contexto español..$^{22}$ Una precariedad étnica que, finalmente, además, se ha convertido en un requisito estructural imprescindible, en una clave de bóveda central, para entender el patrón de crecimiento de la economía española en los últimos años, al sostener la formidable expansión de un modelo económico cuyo dinamismo, competitividad y rentabilidad estuvo apoyada, especialmente, en el auge de sectores de baja productividad y, por lo tanto, en el suministro continuado de trabajo asalariado, flexible y barato, precisamente, aquel que aportaban los trabajadores inmigrantes. Segmentos de trabajo étnico globalizados y vulnerables que, además, al aportar la labor intensiva y barata en sectores como el servicio doméstico o, en general, los servicios manuales ligados a los espacios comunitarios, se han convertido en el pilar fundamental sobre el que se sostienen, actualmente, los transformados estilos de vida, trabajo y ocio de las nuevas clases medias profesionales de los países desarrollados. Sectores sociales que sin el suministro continuado del trabajo desregulado y barato de los migrantes laborales no hubieran podido mantener sus nuevos estilos de vida a un coste económico y social tan bajo.

Un segmento laboral etno-estratificado que constituye, en definitiva, el último escalón laboral de los actuales mercados de trabajo; la última frontera del proceso de informalización y precarización del trabajo y, por tanto, uno de los rasgos estructurales más negativos del actual proceso de transformación social y económica. Una figura, la del migrante laboral, que finalmente retrata o devela algunos de los contornos más significativos, y enmascarados, del presente proceso de globalización económica, aquel que compone su reverso más vulnerable, y que pasa por el crecimiento continuado de figuras laborales precarias y degradadas en el nuevo espacio económico mundializado y, en concreto, en este caso, en los países desarrollados (Castillo, 2009).

Por otro lado, y fuertemente ligadas a esas condiciones de trabajo, la nueva precariedad étnica pasa, también, por la emergencia de condiciones de vida empobrecidas entre amplios sectores de la población inmigrante en las sociedades de acogida. Una vulnerabilidad que es, a la vez, el resultado y la causa de la precariedad en el trabajo, y que se caracteriza por la incertidumbre de los proyectos vitales y migratorios, la escasez e inseguridad de los ingresos, la inestabilidad y debilidad jurídica, los fuertes recortes de las partidas básicas del gasto, un pronunciado deterioro residencial y, finalmente, en múltiples ocasiones, por la dureza de las situaciones vitales (Martínez Veiga, 2003). Un amplio segmento de trabajadores inmigrantes, en definitiva, que reúnen, a la vez, unas pésimas condiciones de trabajo con unas pobres condiciones de vida fuera de él, circunstancias, además, que se ensamblan en una lógica social perversa que transforma la precariedad laboral en pobreza e inseguridad y estas en vulnerabilidad en el mundo del trabajo. ${ }^{23}$

Un segmento social etno-estratificado, una nueva precariedad étnica, que surge, además, como resultado de dos procesos sociales diferentes, pero íntimamente ligados entre sí. Por un lado, a partir de los procesos de estructuración económica presentes en las sociedades de destino, en este caso, a partir del actual proceso de reestructuración económica global de las economías desarrolladas. Ajuste estructural que se ha convertido en un factor decisivo de la actual migración internacional y, por tanto, en

\footnotetext{
${ }^{22}$ Muy diferente, por cierto, al modelo europeo de inmigración de los años 50'-70' donde la incorporación de trabajadores inmigrantes vino derivada, generalmente, de un fuerte incremento de los niveles de productividad. (Castles y Kosack, 1984).

23 "El funcionamiento de una lógica de retroalimentación de las condiciones de vida de los inmigrantes y de las condiciones de trabajo, de las actividades que desempeñan" (Pedreño, 2003: 143).
} 
un vector fundamental a la hora de explicar su incorporación como trabajo precarizado en las economías desarrolladas. La reestructuración, en este sentido, como parte de un proceso más amplio de ajuste a las nuevas condiciones de la globalización, generó una intensa y formidable demanda de trabajo asalariado, barato y flexible, ligada al crecimiento de polos descentralizados de trabajo manual en la industria y los servicios metropolitanos y a la consolidación de unos nuevos estilos de vida entre las nuevas clases medias profesionales que, finalmente, desbordó los límites del mercado de trabajo nativo y se fue, progresivamente, transnacionalizando, sobre hombros de migrantes, convocando e incorporando en condiciones de alta precariedad a trabajadores migrantes procedentes de países en desarrollo.

Pero, al mismo tiempo, es necesario, tener en cuenta y subrayar la importancia de una serie de factores sociales - de genero, etnia, clase, etc.- que aunque no están directamente vinculados a las actuales dinámicas de ajuste estructural, son y se han convertido, en el nutriente social, político e ideológico sobre el que se asientan y se sostienen las condiciones de precariedad de los inmigrantes y, en última instancia, sobre el que se asienten y deslizan los actuales procesos de transformación, fragmentación e informalización económica, social y laboral presentes en las economías desarrolladas. Factores sociales que actúan entrelazados entre sí, enredados en madejas complejas de causas y efectos, constituyendo, fabricando, el fundamento social, las raíces sociales, sobre las que se asienta el proceso de emergencia y consolidación de la nueva precariedad étnica.
Estamos, pues, ante la progresiva formación de un territorio social y laboral, caído y degradado, al interior de las economías desarrolladas. La emergencia, pues, de una nueva precariedad étnica, de un nuevo bloque social etno-estratificado (Castles y Miller, 2004 y Pedreño, 2005) dentro de la estructura social de los países de acogida, sedimentada a partir de la presencia de trabajadores inmigrantes procedentes del Tercer Mundo. Un nuevo segmento social, plenamente incorporado en la dinámica económica y social de nuestras sociedades y, en el caso español, como clave esencial del patrón de crecimiento de los últimos años, que confirma, al tiempo, la presencia creciente dentro de las sociedades desarrolladas de nuevas dinámicas de segmentación social y laboral basadas en la etnicidad, que vienen a sumarse a las clásicas divisiones basadas en el género y la clase social.

Migrantes precarizados que representan, de alguna forma, el descenso en las condiciones de reproducción de los trabajadores que se inaugura, de forma sutil, con la nueva economía política de la globalización, algo que, sin duda, constituye uno de los impresos sociológicos más relevantes que se escenifican en la actual migración internacional. Migrantes que, también, y al mismo tiempo, hablan de las formas de resistencia y respuesta frente a los procesos de empobrecimiento en curso. Migrantes que, en este sentido, no son, solo, corchos a la deriva en el fluir de la historia (Pahl, 1984) sino, también, una fuerza social emergente que ha levantado su propia migración laboral internacional como respuesta frente a las peores consecuencias, la exclusión y el empobrecimiento, del modelo de desarrollo actual. 


\section{BIBLIOGRAFÍA}

ArIAS, P. (1998): “El trabajo femenino a domicilio ayer y hoy.” Sociológica, 13 (37). pp. 77-98.

BORDERÍAS, C. (1991): "Las mujeres, autoras de sus trayectorias personales y familiares: a través del servicio doméstico". Historia y Fuente Oral, 6. 1991. pp. 105 a 121.

CACHÓN, L. (2009): La "España inmigrante": marco discriminatorio, mercado de trabajo y políticas de integración. Barcelona. Anthropos. 2009. 351 p.

CAnales, A. I. (2002): "Migración y trabajo en la era de la globalización: el caso de la migración México-EE.UU en la década de 1990". Papeles de población, julio-septiembre, 33. UAM. México DF. pp. 44 a 81.

CAStillo, J.J. (1999): “A la búsqueda del trabajo perdido y de una sociología capaz de encontrarlo." En A la búsqueda del trabajo perdido, Madrid: Editorial Tecnos. 1999. pp. 147 a 176.

Castillo, J.J. (2002): En la jungla de lo social. Reflexiones y oficio de sociólogo. Madrid. Miño y Dávila. 2002. 204 p.

CASTillo, J. J. (2009): La soledad del trabajador globalizado. Memoria, presente y futuro. Madrid. Ed. La Catarata. 2009. $160 \mathrm{p}$.

Castles, S. y Kosack, G. (1973): Los trabajadores inmigrantes y la estructura de clases en la Europa occidental. México DF. FCE. 1984. 586 p.

Castles S. y Miller, M. (2004): La Era de la Migración. México DF: UAZ/ Porrúa.

Colectivo IOE (2001): "Servicio doméstico e inmigración extracomunitaria". Primera parte: Mujer, Inmigración y Trabajo. Madrid. IMSERSO, MTAS. 2001. pp. 110-451.

Engels, F. (1845) The condition of the working-class in England. USSR. Progress Publishers. 1980.

FOESSA (2008): VI Informe sobre exclusión y desarrollo social en España 2008. Madrid. Fundación Foessa-Cáritas Española. 2008.

Gallino, L. (2002): "La informalización del trabajo en los países desarrollados. Cómo y por qué las condiciones de trabajo en el Norte se están aproximando, a la baja, a las del Sur". Sociología del Trabajo, 45. Primavera de 2002. pp. 7 a 24.

Herrera, G. (2007): “Mujeres ecuatorianas en el trabajo doméstico en España. Prácticas y representaciones de Exclusión e inclusión". En VVAA. Ciudadanía y exclusión: Ecuador y España frente al espejo. Madrid. La Catarata Pp. 279 a 303 .

Herranz, Y. [1997]: "Mujeres dominicanas en el servicio doméstico de Pozuelo-Aravaca". Cuadernos de Relaciones Laborales, 10. Monográfico: Inmigración y trabajo. 1997. pp. 75-101.

Lahera SÁnchez, A. (1998): "Fábrica y Comunidad. Transformación del trabajo e interdisciplinariedad en las Ciencias Sociales del Trabajo." Sociología del Trabajo, 33. pp. 71-102.

Martínez BujÁN, R. (2009): "Política social, migración internacional y trabajo de cuidados: el caso español." En Cachón, L. y Laparra, M. (eds.) Inmigración y políticas sociales. Barcelona. Bellaterra. 2009. pp. 269-293.

Martínez Veiga, U. (1997): La integración social de los inmigrantes extranjeros en España. Madrid. Trotta y Fundación $1^{\circ}$ de Mayo. 1997. 283 p.

Nyberg-Sørensen, N. (2004): "Globalización, género y migración transnacional. El caso de la diáspora dominicana." En Escrivá, A y Ribas, N (Coords) Migración y desarrollo. CSIC, Córdoba.

Oso, L. (1998): La migración hacia España de mujeres jefas de hogar. Madrid: Instituto de la Mujer, MTAS, Serie Estudios n ${ }^{\circ} 52.438 \mathrm{p}$.

PaHL, R.E. [1984]: Divisiones del Trabajo. Madrid. Ministerio de Trabajo y Seguridad Social. 1991. 470 p.

PARELLA, S. [2000]: "El trasvase de desigualdades de clase y etnia entre mujeres: los servicios de proximidad". Papers. Sociología, 60. 2000. Monográfico: Inmigración femenina en el Sur de Europa. Barcelona. pp. 275-289.

Pedreño Cánovas, A. y García Borrego, I. [2005]: "La Inserción de España en las redes migratorias internacionales: configuración social y mercado laboral." Estudios migratorios latinoamericanos, 57. pp. 203 a 247.

Pedreño CÁnovas, A. [2005]: "Sociedades Etnofragmentadas" Cap 4 de VV.AA. La condición inmigrante: exploraciones e investigaciones desde la región de Murcia. Murcia. Univ. De Murcia. 2005. pp. 225 a 250.

Pedreño CÁnovas, A. [2007a]: "Proletarizados y etnificados: la inmigración ecuatoriana en la agricultura intensiva de la Región de Murcia.” En Bretón, V. (et. al.) (eds.) Ciudadanía y Exclusión. Ecuador y España frente al espejo. Madrid. La Catarata. 2007. pp. 225 a 250. 
Pedreño, A. y Castellanos. M. L. (2007b): "La mirada del turista y la corporeidad del trabajo en la reestructuración productiva del sector turístico." Cap. VI de Castillo, J.J. (dir.) El trabajo recobrado. Una evaluación del trabajo realmente existente en España. Buenos Aires. Miño y Dávila. 2005. pp. 221 a 265.

Phizacklea, A. (1990): Unpacking the fashion Industry: Gender, Racism and Class in Production. London. Routledge.

SAn Miguel Del Hoyo, B. [2000]: Elche: la Fábrica dispersa. Los trabajadores de la industria del calzado. Cambios en las condiciones de vida y de trabajo. Alicante. Instituto alicantino de cultura Juan Gil-Albert. 2000. 318 p.

SAssen, S. (1988): La movilidad del trabajo y el Capital. Madrid. Ministerio de Trabajo y Asuntos Sociales. 1993.

SIERRA, J. (1990): El obrero soñado. Ensayo sobre el paternalismo industrial [Asturias, 1860-1917] Madrid: Siglo XXI. $276 \mathrm{p}$.

Valenzuela, A. (et al) (2006): On the Corner. Day labor in the United States. Report of Center for Study or Urban Poverty. Los Angeles. University of California, US. 39 p.

WeIL, S. (1998): Escritos esenciales. ST. Cantabria. 2000.

Tezanos, J. F. (2007): "Nuevas tendencias migratorias y sus efectos sociales y culturales en los países de recepción. Doce tesis sobre inmigración y exclusión social." REIS, 117. pp. 11 a 34.

Zlolniski, C. (2000): "Etnografía de trabajadores informales en un barrio de inmigrantes mexicanos en el Silicon Valley" Revista Mexicana de Sociología, 62. pp. 59-87. 